\title{
Regioselective Oxidative Cation-Olefin Cyclization of Poly-enes: Catalyst Turnover via Hydride Abstraction
}

\section{Supporting Information}

\author{
Charles A. Mullen and Michel R. Gagné \\ Department of Chemistry, University of North Carolina at Chapel Hill, \\ Chapel Hill, North Carolina 27599-3290
}

\section{Table of Contents}

1. General Methods S-1

2. Synthesis of Poly-ene substrates S-2

3. Oxidative Polycyclization Procedures S-4

4. Determination of Stereochemistry S-8

5. Observation of Intermediate I S-8

6. NMR Spectra S-10

1. General Methods. NMR spectra were recorded on a Bruker $400 \mathrm{MHz}$ Avance; chemical shifts are reported in ppm and referenced to residual solvent peaks $\left({ }^{1} \mathrm{H}\right.$ and $\left.{ }^{13} \mathrm{C}\right)$ or to an external standard $\left(85 \% \mathrm{H}_{3} \mathrm{PO}_{4},{ }^{31} \mathrm{P}\right)$. GC was performed on an HP-6890. High-resolution mass spectrometry was performed by the Mass Spectrometry Laboratory at the University of North Carolina at Chapel Hill. 


\section{Synthesis of Poly-ene Substrates:}

General Methods: Synthetic procedures were performed under nitrogen using standard Schlenk techniques or in a nitrogen filled glove box. $\mathrm{CH}_{2} \mathrm{Cl}_{2}, \mathrm{THF}$, and toluene were sparged with argon and passed through a column of activated alumina. MeMgBr solution and $\left(\mathrm{PPh}_{3}\right)_{2} \mathrm{NiCl}_{2}$ were used as received. Diene-phenol substrates $\mathbf{1}^{1}$ and $\mathbf{1 7}^{2}$ were prepared according to a literature procedures. Dienol and trienol substrates 3, 5, 7, 9, 11, 13 and 15 were prepared by $\mathrm{Ni}(0)$ catalyzed ring opening of a substituted 2,3-dhydrofuran with addition of $\mathrm{MeMgBr}$ (Scheme S.1). ${ }^{3}$ The synthesis of $\mathbf{3}$ and $\mathbf{1 1}$ by this method has been previously reported. ${ }^{1}$

Scheme S.1 General Synthesis of Poly-ene Substrates
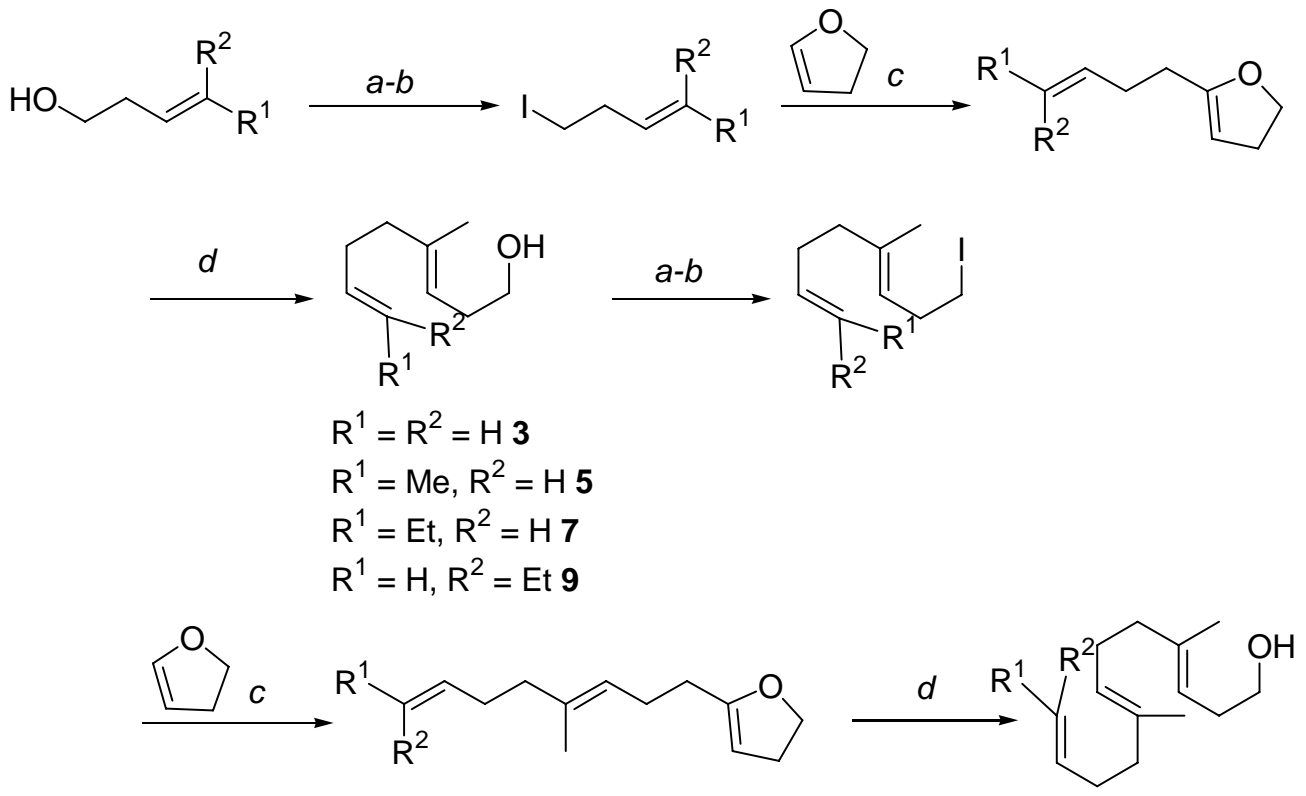

$$
\begin{aligned}
& R^{1}=R^{2}=H 11 \\
& R^{1}=M e, R^{2}=H 13 \\
& R^{1}=H, R^{2}=\text { Et } 15
\end{aligned}
$$

Conditions: (a) $\mathrm{MeSO}_{2} \mathrm{Cl} / \mathrm{Et}_{3} \mathrm{~N}, \mathrm{CH}_{2} \mathrm{Cl}_{2}$; (b) Nal, acetone; (c) $t \mathrm{BuLi}$, THF; (d) $\mathrm{MeMgBr} /\left(\mathrm{PPh}_{3}\right)_{2} \mathrm{NiCl}_{2}$, toluene

1. Koh, J. H.; Mascarenhas, C.; Gagné, M. R. Tetrahedron, 2004, 60, 7405 - 7410.

2. Yamad, S.; Ono, F.; Katagiri, T.; Tanaka, J. Bull. Chem. Soc. Jap. 1977, 50, 750-755.

3. Wadman, S.; Whitby, R.; Yates, C.; Kocienski, P.; Cooper, K. J. Chem. Soc. Chem. Commun. 1987, 241243. 
(3E,7E)-4-methylnona-3,7-dien-1-ol (5): A solution of MeMgBr in ether (18.2 mL, 50.9 mmol) was added to a stirred suspension of $\left(\mathrm{PPh}_{3}\right)_{2} \mathrm{NiCl}_{2}(556 \mathrm{mg}, 0.85 \mathrm{mmol})$ in $60 \mathrm{~mL}$ dry toluene under nitrogen. The resulting red solution was stirred at room temperature for 15 min, and a solution of (E)-5-(hex-4-enyl)-2,3-dihydrofuran $(2.36 \mathrm{~g}, 17.0 \mathrm{mmol})$ in toluene $(20 \mathrm{~mL})$ was added. The mixture was then heated to reflux for $1 \mathrm{~h}$. The reaction was then cooled to $0{ }^{\circ} \mathrm{C}$ and transferred via cannula to a $50 \%$ aqueous solution of $\mathrm{Na}_{2} \mathrm{CO}_{3}$. The mixture was stirred vigorously until it decolorized $(30 \mathrm{~min})$ and was then extracted with diethyl ether. The combined extracts were dried with $\mathrm{MgSO}_{4}$ and the solvent removed in vacuo. The crude material was purified by column chromatography on silica gel eluted with 9:1 hexanes: EtOAc to yield $1.97 \mathrm{~g} 10$ as a colorless oil $(75 \%)$. ${ }^{1} \mathrm{H}$ NMR $\left(\mathrm{CDCl}_{3}, 400 \mathrm{MHz}\right)$ : $\delta 5.36(\mathrm{~m}, 2 \mathrm{H}), 5.10(\mathrm{~m}, 1 \mathrm{H}), 3.59$ (q, $J=5.6 \mathrm{~Hz}, 2 \mathrm{H}), 2.26(\mathrm{q}, J=6.8 \mathrm{~Hz}, 2 \mathrm{H}), 2.07(\mathrm{~m}$, $4 \mathrm{H}), 1.62(\mathrm{~d}, J=5.2 \mathrm{~Hz}, 3 \mathrm{H}), 1.61(\mathrm{~s}, 3 \mathrm{H}) .{ }^{13} \mathrm{C} \mathrm{NMR}\left(100 \mathrm{MHz}, \mathrm{CDCl}_{3}\right): \delta$ 138.7, 130.9, 125.0, 120.0, 62.3, 39.7, 31.4, 31.0, 17.9, 16.1. HRMS expected for $\mathrm{C}_{10} \mathrm{H}_{18} \mathrm{O}+\mathrm{H}: 155.144$. Found: 155.156 .

(3E,7E)-4-methyldeca-3,7-dien-1-ol (7): A procedure similar to that used for synthesis of 5 was followed. The crude material was purified by column chromatography on silica gel eluted with 9:1 hexanes: EtOAc to yield $\mathbf{1 1}$ as a colorless oil (78\%). ${ }^{1} \mathrm{H} \mathrm{NMR}\left(\mathrm{CDCl}_{3}, 400\right.$ MHz): $\delta 5.43(\mathrm{~m}, 1 \mathrm{H}), 5.33(\mathrm{~m}, 1 \mathrm{H}), 5.09(\mathrm{t}, J=7.2 \mathrm{~Hz}, 1 \mathrm{H}), 3.58(\mathrm{q}, J=6.4 \mathrm{~Hz}, 2 \mathrm{H}), 2.26$ (q, $J=6.8 \mathrm{~Hz}, 2 \mathrm{H}), 2.08(\mathrm{~m}, 4 \mathrm{H}), 1.95$ (quintet, $J=7.2 \mathrm{~Hz}, 2 \mathrm{H}), 1.61(\mathrm{~s}, 3 \mathrm{H}), 1.42(\mathrm{t}, J=6.0$ $\mathrm{Hz}, 1 \mathrm{H}), 0.93(\mathrm{t}, J=7.2 \mathrm{~Hz}, 3 \mathrm{H}) .{ }^{13} \mathrm{C} \mathrm{NMR}\left(100 \mathrm{MHz}, \mathrm{CDCl}_{3}\right): \delta 138.7,132.3,128.6$, 120.0, 62.3, 39.8, 31.4, 31.0, 25.5, 16.2, 13.9. HRMS expected for $\mathrm{C}_{11} \mathrm{H}_{20} \mathrm{O}+\mathrm{H}: 169.159$. Found: 169.157.

(3E,7Z)-4-methyldeca-3,7-dien-1-ol (9): A procedure similar to that used for synthesis of $\mathbf{5}$ was followed. The crude material was purified by column chromatography on silica gel eluted with 9:1 hexanes: EtOAc to yield 12 as a colorless oil (56\%). ${ }^{1} \mathrm{H} \mathrm{NMR}\left(\mathrm{CDCl}_{3}, 400\right.$ MHz): ${ }^{1} \mathrm{H}$ NMR (400 MHz, $\left.\mathrm{CDCl}_{3}\right) \delta 5.35(\mathrm{~m}, 1 \mathrm{H}), 5.27(\mathrm{~m}, 1 \mathrm{H}), 5.11(\mathrm{t}, J=7.2 \mathrm{~Hz}, 1 \mathrm{H})$, 3.59 (q, $J=6.0 \mathrm{~Hz}, 2 \mathrm{H}), 2.27$ (q, $J=6.8 \mathrm{~Hz}, 2 \mathrm{H}), 2.13(\mathrm{q}, J=7.6 \mathrm{~Hz}, 2 \mathrm{H}), 2.02(\mathrm{~m}, 4 \mathrm{H})$, $1.62(\mathrm{~s}, 3 \mathrm{H}), 1.44(\mathrm{t}, J=5.6 \mathrm{~Hz}, 1 \mathrm{H}), 0.93(\mathrm{t}, J=7.6 \mathrm{~Hz}, 3 \mathrm{H}) .{ }^{13} \mathrm{C}\left\{{ }^{1} \mathrm{H}\right\}$ NMR $(100 \mathrm{MHz}$, 
$\left.\mathrm{CDCl}_{3}\right) \delta 138.6,131.9,128.5,120.1,62.3,39.7,31.4,25.5,20.5,16.1,14.4 . \quad$ HRMS expected for $\mathrm{C}_{11} \mathrm{H}_{20} \mathrm{O}+\mathrm{H}: 169.159$. Found: 169.159 .

(3E,7E,11E)-4,8-dimethyltrideca-3,7,11-trien-1-ol (13): A procedure similar to that used for synthesis of $\mathbf{5}$ was followed.. The crude material was purified by column chromatography on silica gel eluted with 9:1 hexanes: EtOAc to yield $\mathbf{1 4}$ as a colorless oil (62\%). ${ }^{1} \mathrm{H} \mathrm{NMR}\left(\mathrm{CDCl}_{3}, 400 \mathrm{MHz}\right) \delta 5.39(\mathrm{~m}, 2 \mathrm{H}), 5.09$ (m, 2H), 3.59 (q, $\left.J=6.4 \mathrm{~Hz}, 2 \mathrm{H}\right)$, $2.27(\mathrm{q}, J=6.8 \mathrm{~Hz}, 2 \mathrm{H}), 2.02(\mathrm{~m}, 8 \mathrm{H}), 1.62(\mathrm{~d}, J=5.2 \mathrm{~Hz}, 3 \mathrm{H}), 1.61(\mathrm{~s}, 3 \mathrm{H}), 1.58(\mathrm{~s}, 3 \mathrm{H})$, $1.37(\mathrm{t}, J=3.2 \mathrm{~Hz}, 1 \mathrm{H}) .{ }^{13} \mathrm{C} \mathrm{NMR}\left(100 \mathrm{MHz}, \mathrm{CDCl}_{3}\right): \delta 138.9,135.1,131.1,124.7,124.0$, $119.8,62.4,39.8,39.7,31.5,31.2,26.4,17.9,16.2,16.0$. HRMS expected for $\mathrm{C}_{15} \mathrm{H}_{26} \mathrm{O}+\mathrm{H}$ : 245.188. Found: 245.186.

(3E,7E,11Z)-4,8-dimethyltetradeca-3,7,11-trien-1-ol (15): A procedure similar to that used for synthesis of $\mathbf{1 0}$ was followed.. The crude material was purified by column chromatography on silica gel eluted with 9:1 hexanes: EtOAc to yield $\mathbf{1 4}$ as a colorless oil (62\%). ${ }^{1} \mathrm{H}$ NMR (400 MHz, $\left.\mathrm{CDCl}_{3}\right) \delta 5.31(\mathrm{~m}, 2 \mathrm{H}), 5.09$ (m, 2H), 3.59 (q, $\left.J=6.4 \mathrm{~Hz}, 2 \mathrm{H}\right)$, $2.27(\mathrm{q}, J=6.8 \mathrm{~Hz}, 2 \mathrm{H}), 2.09(\mathrm{~m}, 4 \mathrm{H}), 2.00(\mathrm{~m}, 6 \mathrm{H}), 1.62(\mathrm{~s}, 3 \mathrm{H}), 1.58(\mathrm{~s}, 3 \mathrm{H}), 1.38(\mathrm{t}, J=$ $6.0 \mathrm{~Hz}, 1 \mathrm{H}), 0.93(\mathrm{t}, J=7.2 \mathrm{~Hz}, 3 \mathrm{H}) .{ }^{13} \mathrm{C} \mathrm{NMR}\left(100 \mathrm{MHz}, \mathrm{CDCl}_{3}\right) \delta 138.9,135.0,131.6$, $128.7,124.1,119.8,62.4,39.8,39.6,31.4,26.4,25.6,20.5,16.2,16.0,14.4$. HRMS expected for $\mathrm{C}_{16} \mathrm{H}_{28} \mathrm{O}+\mathrm{H}: 237.222$. Found: 237.222.

\section{Oxidative Polycyclizations:}

General: $\mathrm{MeNO}_{2}$ and $\mathrm{EtNO}_{2}$ were distilled from $\mathrm{CaH}_{2} . \mathrm{Ph}_{3} \mathrm{COMe}^{4}$ resin and (cod) $\mathrm{PtCl}_{2}{ }^{5}$ were prepared according to literature procedures. (dppe) $\mathrm{PtI}_{2}$ was prepared from dppe and (cod)PtI ${ }_{2}$.

Method A: To a $13.3 \mathrm{mM}$ solution of (dppe) $\mathrm{PtI}_{2}$ (typically $0.02 \mathrm{mmol}$ ) in $\mathrm{EtNO}_{2}$ was added 2.2 equiv. $\mathrm{AgBF}_{4}$. After stirring $1 \mathrm{~h}$ in the dark, 21.0 equiv. $\mathrm{Ph}_{3} \mathrm{COMe}$ on polystyrene resin, and 10 equiv. substrate were added and the mixture was stirred at room temperature in

4. Fyles, T. M.; Leznoff, C. C. Can. J. Chem. 1976, 54, 935 - 942.

5. Drew, D.; Doyle, J. R. Inorg. Syn. 1990, 28, 346-349. 
the dark until the reaction was complete by GC (typically 6-14 h). The reaction mixture was then quenched by passage through plug of silica gel eluted with ether. Solvent was then removed in vacuo and the residue purified by column chromatography.

Method B: To a $13.3 \mathrm{mM}$ solution of (dppe) $\mathrm{PtI}_{2}$ (typically $0.02 \mathrm{mmol}$ ) in $\mathrm{EtNO}_{2}$ was added 2.2 equiv. $\mathrm{AgBF}_{4}$. After stirring $1 \mathrm{~h}$ in the dark, 21.0 equiv. $\mathrm{Ph}_{3} \mathrm{COMe}$ on polystyrene resin, and 10 equiv. substrate were added and the mixture was stirred at room temperature in the dark until the reaction was complete by GC (typically 6-14 h). Water $(3 \mathrm{~mL})$ was then added and the mixture was extracted with pentane $(3 \times 5 \mathrm{~mL})$. Pentane was then remove in vacuo at $0^{\circ} \mathrm{C}$ and the reside purified by column chromatography.

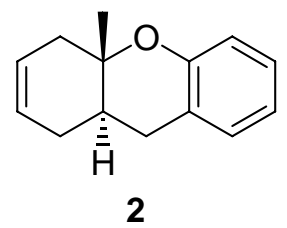

2. Prepared from 1 by Method A. Crude material purified by flash chromatography on silica gel eluted with 3:97 ethyl acetate:hexanes. $29.2 \mathrm{mg}$ (73\% yield). ${ }^{1} \mathrm{H}$ NMR (400 MHz, $\left.\mathrm{CDCl}_{3}\right) \delta 7.05(\mathrm{t}, J=7.6 \mathrm{~Hz}, 1 \mathrm{H}), 7.01(\mathrm{~d}, J=7.6 \mathrm{~Hz}, 1 \mathrm{H}), 6.77(\mathrm{q}, J=7.6 \mathrm{~Hz}), 5.63(\mathrm{~m}$, 2H), $2.71(\mathrm{dd}, J=16.4 \mathrm{~Hz}, 5.2 \mathrm{~Hz}, 1 \mathrm{H}), 2.51(\mathrm{~m}, 1 \mathrm{H}), 2.35(\mathrm{~m}, 3 \mathrm{H}), 2.15$ (m, 1H), 1.78 (m, $1 \mathrm{H}), 1.20(\mathrm{~s}, 3 \mathrm{H}) .{ }^{13} \mathrm{C} \mathrm{NMR}\left(100 \mathrm{MHz}, \mathrm{CDCl}_{3}\right) \delta 153.5,129.3,127.3,125.4,125.2,121.5$, 119.7, 117.0, 75.7, 39.9, 35.1, 31.9, 28.9, 17.4. HRMS expected for $\mathrm{C}_{14} \mathrm{H}_{16} \mathrm{O}+\mathrm{H}: 201.128$. Found: 201.127.

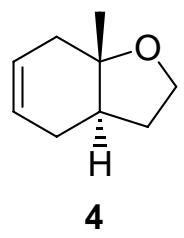

4. Prepared from 3 by Method B. Crude material purified by flash chromatography on silica gel with eluted with 3:97 diethyl ether:pentane. $23.0 \mathrm{mg}$ (84\% yield) ${ }^{1} \mathrm{H}$ NMR (400 $\left.\mathrm{MHz}, \mathrm{CDCl}_{3}\right) \delta 5.62(\mathrm{~m}, 2 \mathrm{H}), 3.90(\mathrm{dd}, J=8.4 \mathrm{~Hz}, 3.2 \mathrm{~Hz}, 1 \mathrm{H}), 3.84(\mathrm{~m}, 1 \mathrm{H}), 2.32(\mathrm{~m}, 1 \mathrm{H})$, $2.23(\mathrm{~m}, 2 \mathrm{H}), 1.96(\mathrm{~m}, 1 \mathrm{H}), 1.64-1.86(\mathrm{~m}, 3 \mathrm{H}), 0.93(\mathrm{~s}, 3 \mathrm{H}) .{ }^{13} \mathrm{C} \mathrm{NMR}\left(100 \mathrm{MHz}, \mathrm{CDCl}_{3}\right)$ $\delta 126.5$ (2C), 79.5, 65.0, 43.3, 40.1, 29.0, 28.4, 17.1. HRMS expected for $\mathrm{C}_{9} \mathrm{H}_{14} \mathrm{O}+\mathrm{H}$ : 139.112. Found: 139.110. 


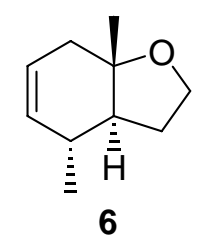

6. Prepared from 5 by Method A. Crude material purified by flash chromatography on silica gel eluted with 3:97 diethyl ether:pentane. $20.3 \mathrm{mg}(67 \%$ yield $){ }^{1} \mathrm{H} \mathrm{NMR}\left(\mathrm{CDCl}_{3}, 400\right.$ $\mathrm{MHz}) \delta 5.56(\mathrm{~m}, 1 \mathrm{H}), 5.43(\mathrm{~m}, 1 \mathrm{H}), 3.92(\mathrm{dt}, J=9.6 \mathrm{~Hz}, 3.2 \mathrm{~Hz}, 1 \mathrm{H}), 3.83(\mathrm{q}, J=8.4 \mathrm{~Hz})$, $2.18(\mathrm{~m}, 2 \mathrm{H}), 2.00(\mathrm{~m}, 2 \mathrm{H}), 1.63(\mathrm{~m}, 1 \mathrm{H}), 1.39(\mathrm{~m}, 1 \mathrm{H}), 1.04(\mathrm{~d}, J=6.8 \mathrm{~Hz}, 3 \mathrm{H}), 0.93$ (s, $3 \mathrm{H}) .{ }^{13} \mathrm{C} \mathrm{NMR}\left(100 \mathrm{MHz}, \mathrm{CDCl}_{3}\right) \delta 133.2,125.3,79.8,65.2,39.9,34.8,27.1,19.7,17.9$. HRMS expected for $\mathrm{C}_{10} \mathrm{H}_{16} \mathrm{O}+\mathrm{H}$ 153.128. Found: 153.126 .

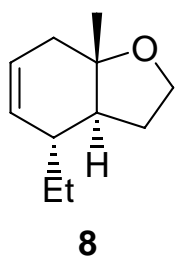

8. Prepared from 7 by Method A. Crude material purified by flash chromatography on silica gel eluted with 3:97 diethyl ether:pentane. $19.8 \mathrm{mg}$ (65\% yield). ${ }^{1} \mathrm{H}$ NMR ${ }^{1} \mathrm{H} \mathrm{NMR}$ $\left(400 \mathrm{MHz}, \mathrm{CDCl}_{3}\right) \delta 5.60(\mathrm{~m}, 1 \mathrm{H}), 5.54(\mathrm{~m}, 1 \mathrm{H}), 3.91(\mathrm{dt}, J=8.3 \mathrm{~Hz}, 2.8 \mathrm{~Hz}, 1 \mathrm{H}), 3.84(\mathrm{q}$, $J=8.4 \mathrm{~Hz}, 1 \mathrm{H}), 2.19$ (m, 2H), 2.00 (m, 1H), 1.86 (bm, 1H), 1.57 - 1.67 (m, 2H), 1.45 - 1.55 $(\mathrm{m}, 2 \mathrm{H}), 1.33(\mathrm{~m}, 1 \mathrm{H}), 0.95(\mathrm{~s}, 3 \mathrm{H}), 0.93(\mathrm{t}, J=8.0 \mathrm{~Hz}) \cdot{ }^{13} \mathrm{C}\left\{{ }^{1} \mathrm{H}\right\} \mathrm{NMR}\left(100 \mathrm{MHz}, \mathrm{CDCl}_{3}\right) \delta$ $130.9,125.9,80.0,65.2,48.6,41.3,40.0,27.3,26.6,17.8,11.0$. HRMS expected for $\mathrm{C}_{11} \mathrm{H}_{18} \mathrm{O}+\mathrm{H}:$ 167.144. Found: 167.142 .

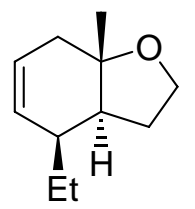

10

10. Prepared from 9 by Method A. Crude material purified by flash chromatography on silica gel eluted with 3:97 diethyl ether:pentane. $21.9 \mathrm{mg}(72 \%$ yield $) .{ }^{1} \mathrm{H} \mathrm{NMR}\left(\mathrm{CDCl}_{3}\right.$, $400 \mathrm{MHz}) \delta 5.78(\mathrm{~m}, 1 \mathrm{H}), 5.62(\mathrm{~m}, 1 \mathrm{H}), 3.92(\mathrm{~m}, 1 \mathrm{H}), 3.83(\mathrm{q}, J=8.0 \mathrm{~Hz}, 1 \mathrm{H}), 2.30$ (br m, 1H), $2.20(\mathrm{~m}, 1 \mathrm{H}), 1.98(\mathrm{~m}, 2 \mathrm{H}), 1.56(\mathrm{~m}, 1 \mathrm{H}), 1.29(\mathrm{~m}, 2 \mathrm{H}), 0.99(\mathrm{~s}, 3 \mathrm{H}), 0.95$ (t, J = 7.6 $\mathrm{Hz}, 3 \mathrm{H}) .{ }^{13} \mathrm{C} \mathrm{NMR}\left(100 \mathrm{MHz}, \mathrm{CDCl}_{3}\right) \delta 130.1,124.9,78.6,64.6,46.2,40.3,40.1,25.2$, 21.7, 20.5, 13.2. HRMS expected for $\mathrm{C}_{11} \mathrm{H}_{18} \mathrm{O}+\mathrm{H}$ 167.144. Found: 167.143. 


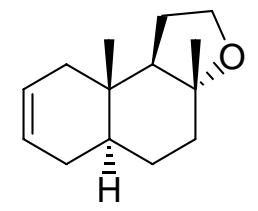

12

12. Prepared from 11 by Method A. Crude material purified by flash chromatography on silica gel eluted with 2:98 diethyl ether:pentane. $37.1 \mathrm{mg}$ (90\% yield). ${ }^{1} \mathrm{H} \mathrm{NMR}\left(\mathrm{CDCl}_{3}, 400\right.$ MHz) $\delta 5.63(\mathrm{~m}, 1 \mathrm{H}), 5.53(\mathrm{~m}, 1 \mathrm{H}), 3.92(\mathrm{~m}, 1 \mathrm{H}), 3.83(\mathrm{q}, J=8.4 \mathrm{~Hz}, 1 \mathrm{H}), 1.87(\mathrm{~m}, 1 \mathrm{H})$, $1.82(\mathrm{~m}, 2 \mathrm{H}), 1.78$ (m, 1H), 1.56 (m, 2H), 1.40 (m, 4H), $1.26(\mathrm{~m}, 2 \mathrm{H}), 1.08(\mathrm{~s}, 3 \mathrm{H}), 0.73(\mathrm{~s}$, $3 \mathrm{H}) .{ }^{13} \mathrm{C} \mathrm{NMR}\left(100 \mathrm{MHz}, \mathrm{CDCl}_{3}\right) \delta 126.7,125.2,80.0,67.8,57.7,42.9,40.8,38.6,34.0$, 28.7, 27.5, 22.8, 20.5, 12.0. HRMS expected for $\mathrm{C}_{14} \mathrm{H}_{22} \mathrm{O}+\mathrm{H}: 207.175$. Found: 207.173.

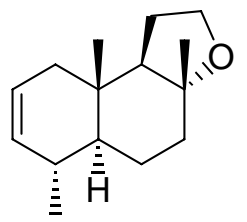

14

14. Prepared from 13 by Method A. Crude material purified by flash chromatography on silica gel eluted with 3:97 diethyl ether:pentane. $37.1 \mathrm{mg}\left(90 \%\right.$ yield). ${ }^{1} \mathrm{H}$ NMR $\left(\mathrm{CDCl}_{3}, 400\right.$ MHz) $\delta 5.47$ (m, 2H), $3.90(\mathrm{~m}, 1 \mathrm{H}), 3.83(\mathrm{q}, J=8.0 \mathrm{~Hz}, 1 \mathrm{H}), 1.87(\mathrm{~m}, 2 \mathrm{H}), 1.78(\mathrm{~m}, 5 \mathrm{H})$, $1.14(\mathrm{~m}, 1 \mathrm{H}), 1.08(\mathrm{~s}, 3 \mathrm{H}), 0.98(\mathrm{~d}, J=6.8 \mathrm{~Hz}, 3 \mathrm{H}), 1.08(\mathrm{~m}, 1 \mathrm{H}), 0.76(\mathrm{~s}, 3 \mathrm{H}) .{ }^{13} \mathrm{C}$ NMR $\left(100 \mathrm{MHz}, \mathrm{CDCl}_{3}\right) \delta 133.7,123.8,79.8,64.8,57.9,50.4,40.8,38.8,34.7,32.2,24.3,22.9$, 19.7, 12.9. HRMS expected for $\mathrm{C}_{15} \mathrm{H}_{24} \mathrm{O}+\mathrm{H}: 221.191$. Found: 221.188 .

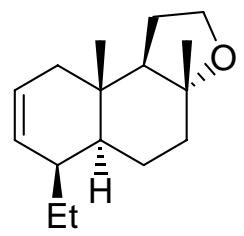

16

16. Prepared from $\mathbf{1 5}$ by Method A. Crude material purified by flash chromatography on silica gel eluted with 3:97 diethyl ether:pentane. (21.0 mg (45\% yield). ${ }^{1} \mathrm{H}$ NMR $\left(\mathrm{CDCl}_{3}\right.$, $400 \mathrm{MHz}) \delta 5.87$ (m, 1H), $5.55(\mathrm{~m}, 1 \mathrm{H}), 3.91(\mathrm{~m}, 1 \mathrm{H}), 3.83(\mathrm{q}, J=8.0 \mathrm{~Hz}, 1 \mathrm{H}), 1.95(\mathrm{~m}, 2 \mathrm{H})$, $1.83(\mathrm{~m}, 2 \mathrm{H}), 1.75$ (m, 3H), 1.58 (m, 4H), 1.43 (m, 2H), 1.22 (m, 2H), 1.09 (s, 3H), 0.93 (t, $J$ 
$=7.6 \mathrm{~Hz}, 3 \mathrm{H}), 0.78(\mathrm{~s}, 3 \mathrm{H}) .{ }^{13} \mathrm{C} \mathrm{NMR}\left(100 \mathrm{MHz}, \mathrm{CDCl}_{3}\right) \delta 130.2,123.8,79.9,64.8,58.8$, 46.3, 41.4, 40.9, 39.0, 34.5, 25.1, 22.6, 22.2, 20.3, 15.6, 13.6. HRMS expected for $\mathrm{C}_{16} \mathrm{H}_{26} \mathrm{O}+\mathrm{H}: 235.206$. Found: 235.202.

\section{Determination of Stereochemistry.}

Trans ring junctions were verified by hydrogenation $(\mathrm{Pd} / \mathrm{C}, \mathrm{MeOH})$ of products $\mathbf{2 ,} \mathbf{4 , 1 2}$ and 14 to known saturated cyclic compounds. ${ }^{1,6,7}$ The remaining products were assigned trans ring junctions by analogy.

The relative stereochemistry of the C-4 stereocenter to the ring junctions in product $\mathbf{6}$ was determined by a lack of an nOe cross peak between methyl groups in a 2-D NOESY NMR experiment. Product 8 (C-4 Et rather than $\mathrm{Me}$ ) was then assigned the same stereochemistry by analogy. Product $\mathbf{1 0}$ was assigned the opposite stereochemistry at C-4 based on the fact that it is the only reasonable structure that differs from $\mathbf{8}$.

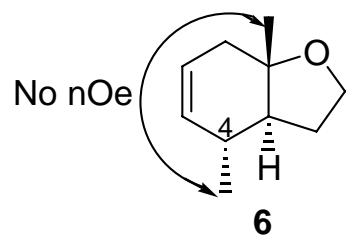

The stereochemistry for $\mathbf{1 4}$ was determined by hydrogenation and comparison of the ${ }^{1} \mathrm{H}$ NMR data with literature data (all possible stereoisomers are reported). ${ }^{6}$ Since the stereochemistry of $\mathbf{1 4}$ (trans ring junctions and C-4) was in agreement with that of $\mathbf{1 0}$, product $\mathbf{1 6}$ was assigned the opposite stereochemistry in analogy to $\mathbf{1 0}$.

\section{Observation of Intermediate with $\beta$-agostic interaction.}

Procedure. In a nitrogen filled glove-box $21.2 \mathrm{mg}(0.025 \mathrm{mmol})(\mathrm{dppe}) \mathrm{PtI}_{2}$ and 10.2 $\mathrm{mg}(0.052 \mathrm{mmol}) \mathrm{AgBF}_{4}$ were stirred in $1 \mathrm{~mL} \mathrm{CD} \mathrm{CDO}_{2}$ for $1 \mathrm{~h}$. AgI was removed by filtration through a PTFE filter. The solution was then cooled to $-78^{\circ} \mathrm{C}$ and $8.4 \mathrm{mg}(0.049$ mmol) $\mathrm{Ph}_{2} \mathrm{NH}$ and $10.0 \mathrm{mg}(0.049 \mathrm{mmol}) 1$ were then added and the mixture loaded into an

6. Ohloff, G.; Giersch, W.; Pickenhagen, A. F.; Frei, B. Hel. Chem. Acta 1985, 68, $2022-2029$.

7. Nishizawa, M.; Iwamoto, Y; Takao, H.; Imagawa, H.; Sugihara, T. Org. Lett. 2000, 2, 1685 - 1687. 
NMR tube and warmed to $0^{\circ} \mathrm{C}$. After $3 \mathrm{~h}$ complete conversion to the $\mathrm{P}_{2} \mathrm{Pt}$-alkyl can be observed by ${ }^{31} \mathrm{P}$ NMR (Figure S.1). ${ }^{31} \mathrm{P}$ NMR $\left(162 \mathrm{MHz}, \mathrm{CD}_{3} \mathrm{NO}_{2}\right) \delta 48.4\left(\mathrm{~s}, J_{\mathrm{P}-\mathrm{Pt}}=1542\right.$ $\mathrm{Hz}), 41.0\left(\mathrm{~s}, J_{\mathrm{P}-\mathrm{Pt}}=4573 \mathrm{~Hz}\right)$.

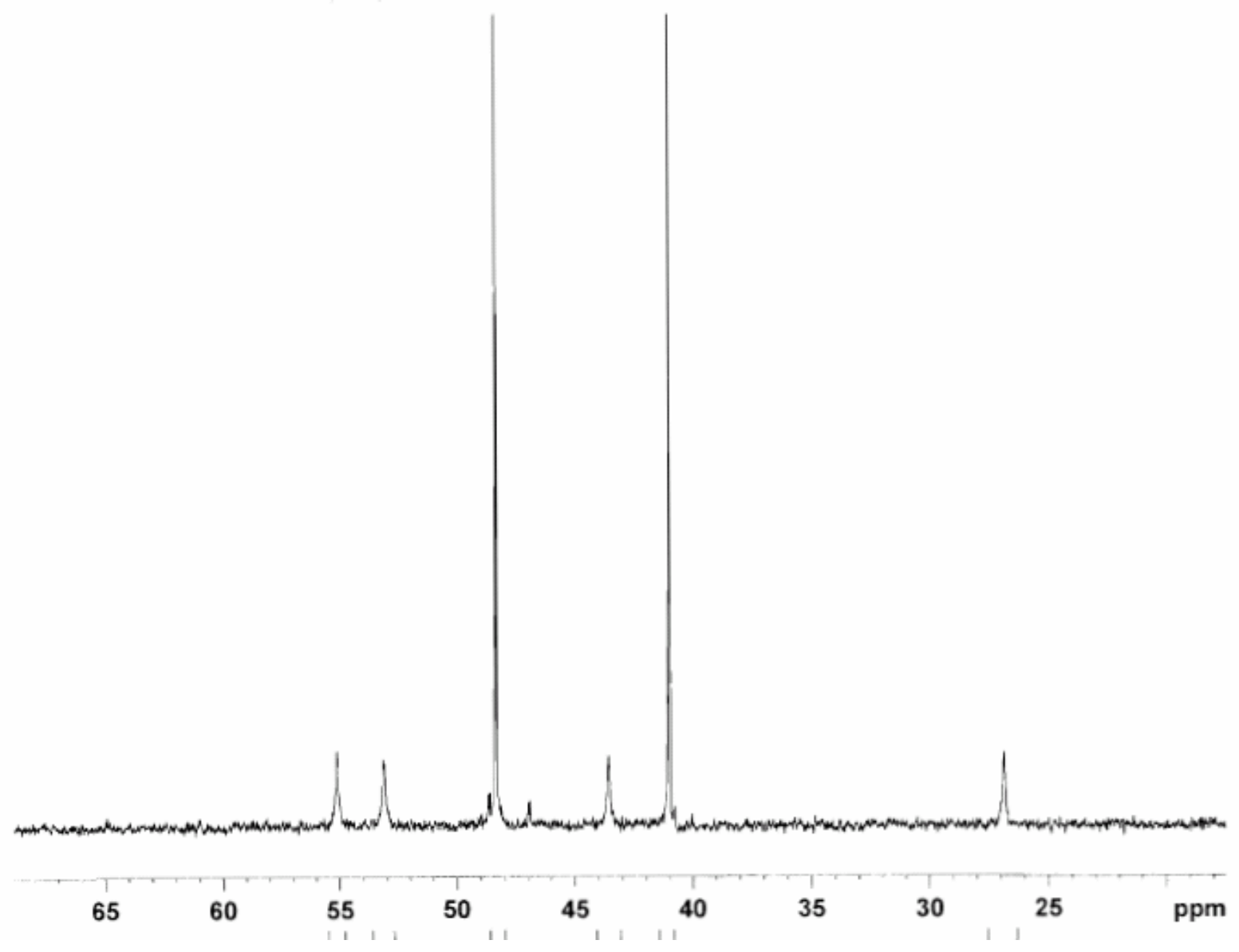

Figure S.1: ${ }^{31} \mathrm{P}$ NMR of $\mathrm{I}$. 
$\nabla 60^{\circ} \mathrm{T}$

$69 T^{\circ} \tau \square$

9ES. I

$\varepsilon \varpi \varepsilon^{*} 乙-$

$6\left\llcorner\varepsilon^{*} 乙\right.$

$\nabla 6 \varepsilon^{\circ} Z$

दहग 2

โ6 $0^{\circ} \mathrm{Z}$

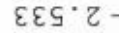

$9 \angle 9^{\circ} Z$

$569^{\circ} \mathrm{Z}-$

$86 \tau^{*} \varepsilon$
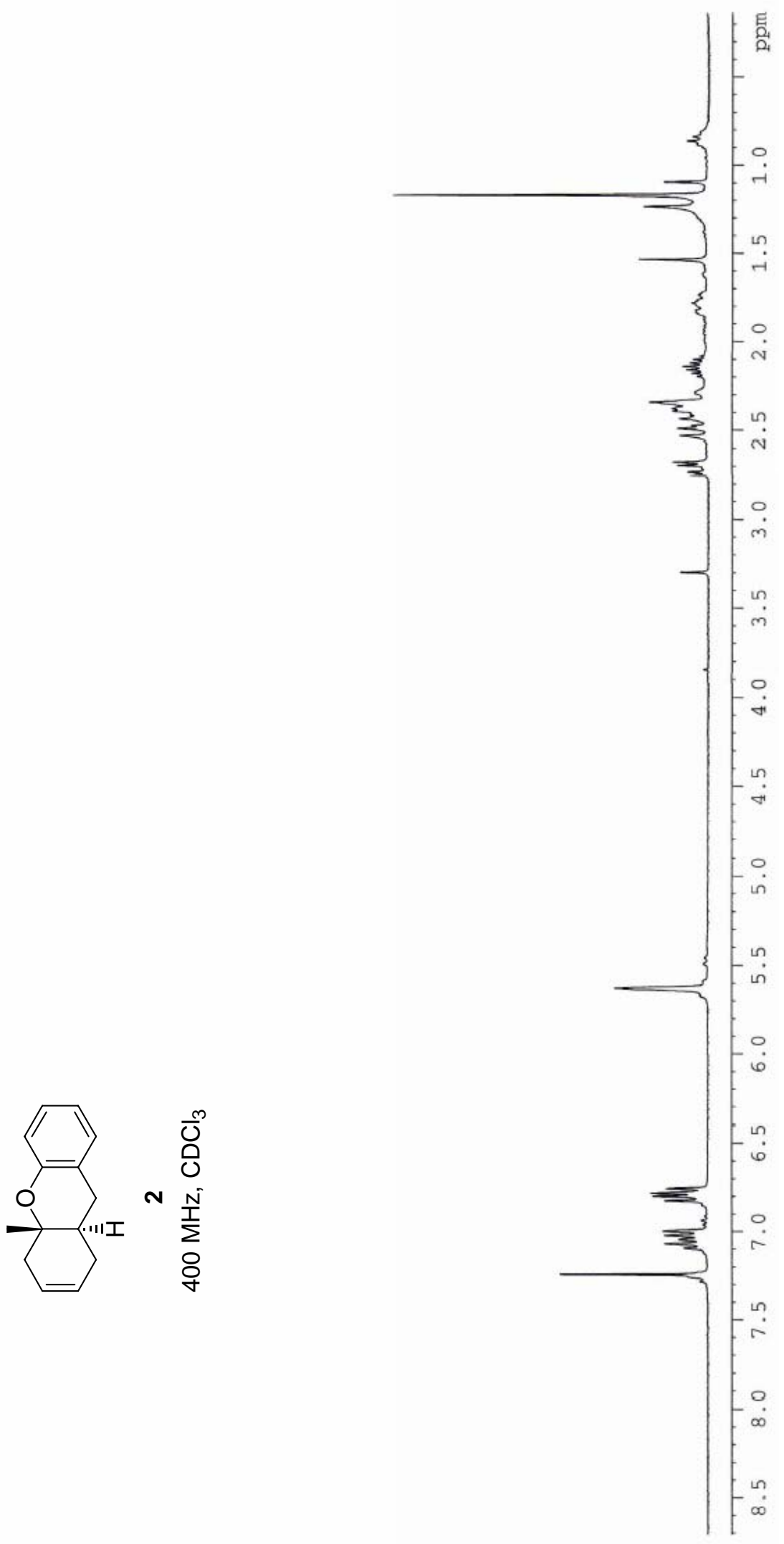

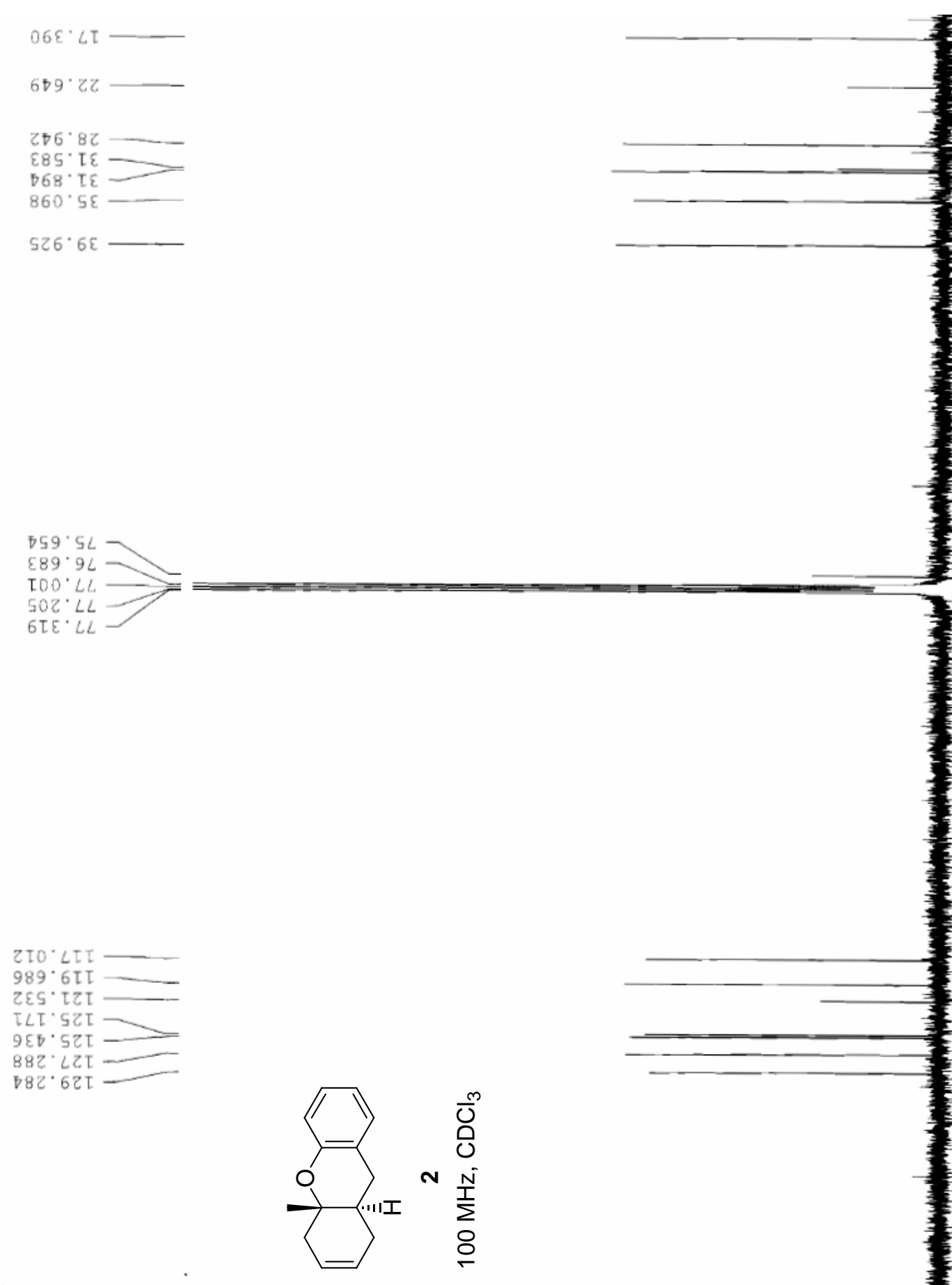

'हIS ${ }^{*} \varepsilon \mathrm{I} \longrightarrow$

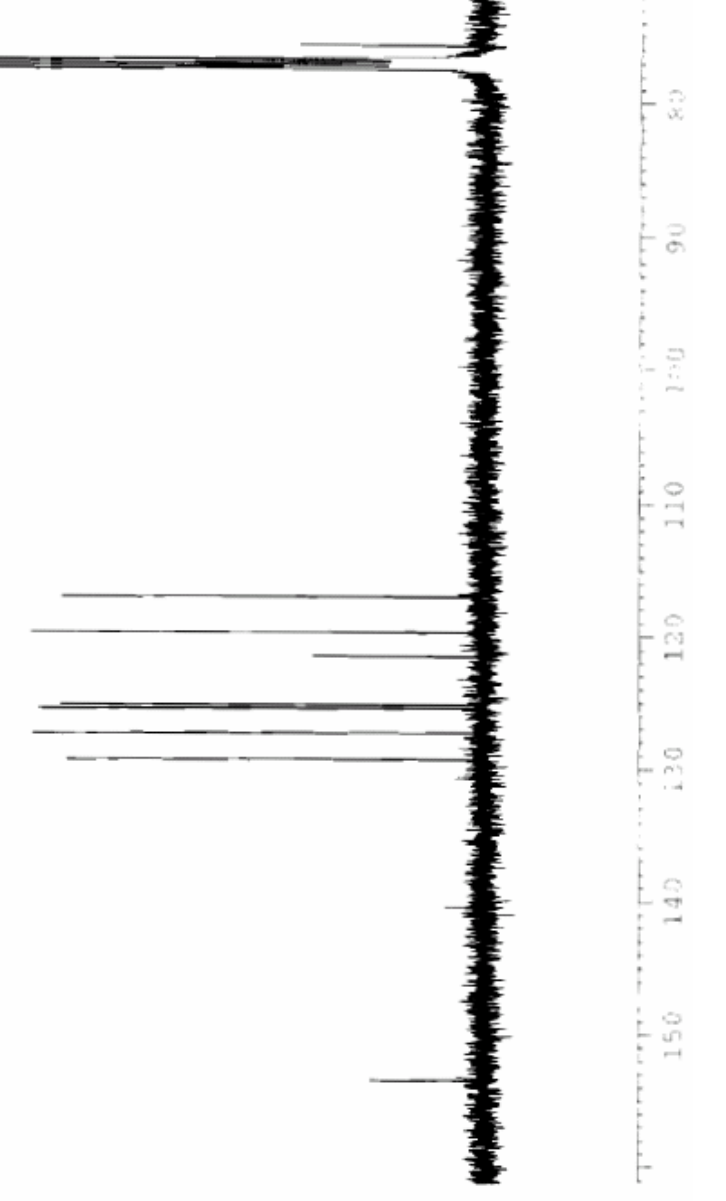



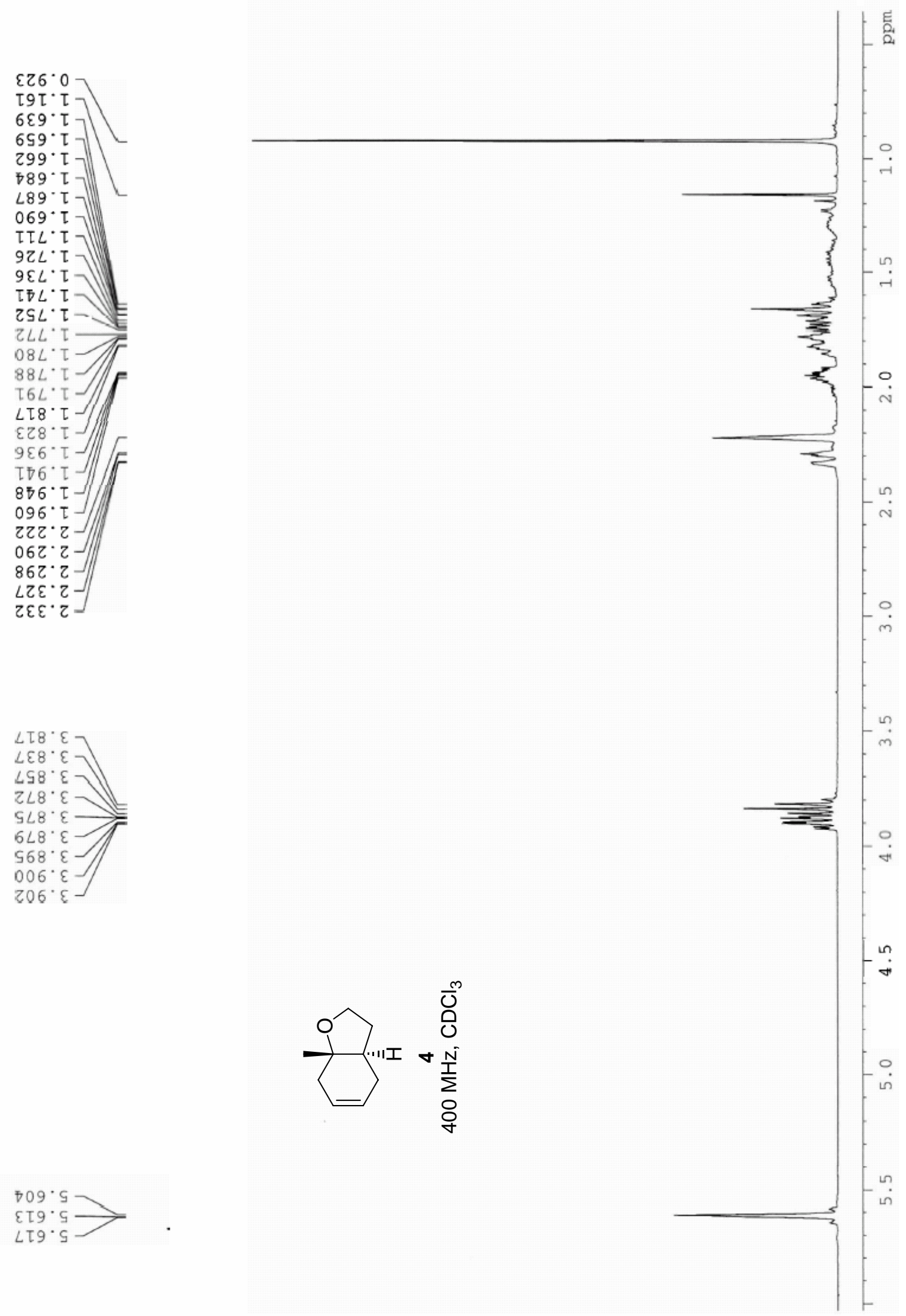

$709^{\circ} \varsigma$

हT . द . $\angle T 9 \cdot \mathrm{S} \longrightarrow$ 
$\varepsilon 90^{\circ} \mathrm{LI}$

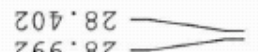

$266.82 \longrightarrow$

$\angle S O{ }^{\circ} O \bar{D}$

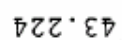

$\nabla 66^{\circ} \nabla 9$

$989 \cdot 9 L$

$800^{\circ} \mathrm{LL}$

$802.2 L$

$69 \varepsilon \cdot 6 L$

$\overline{787.92 \tau \longrightarrow ~}$
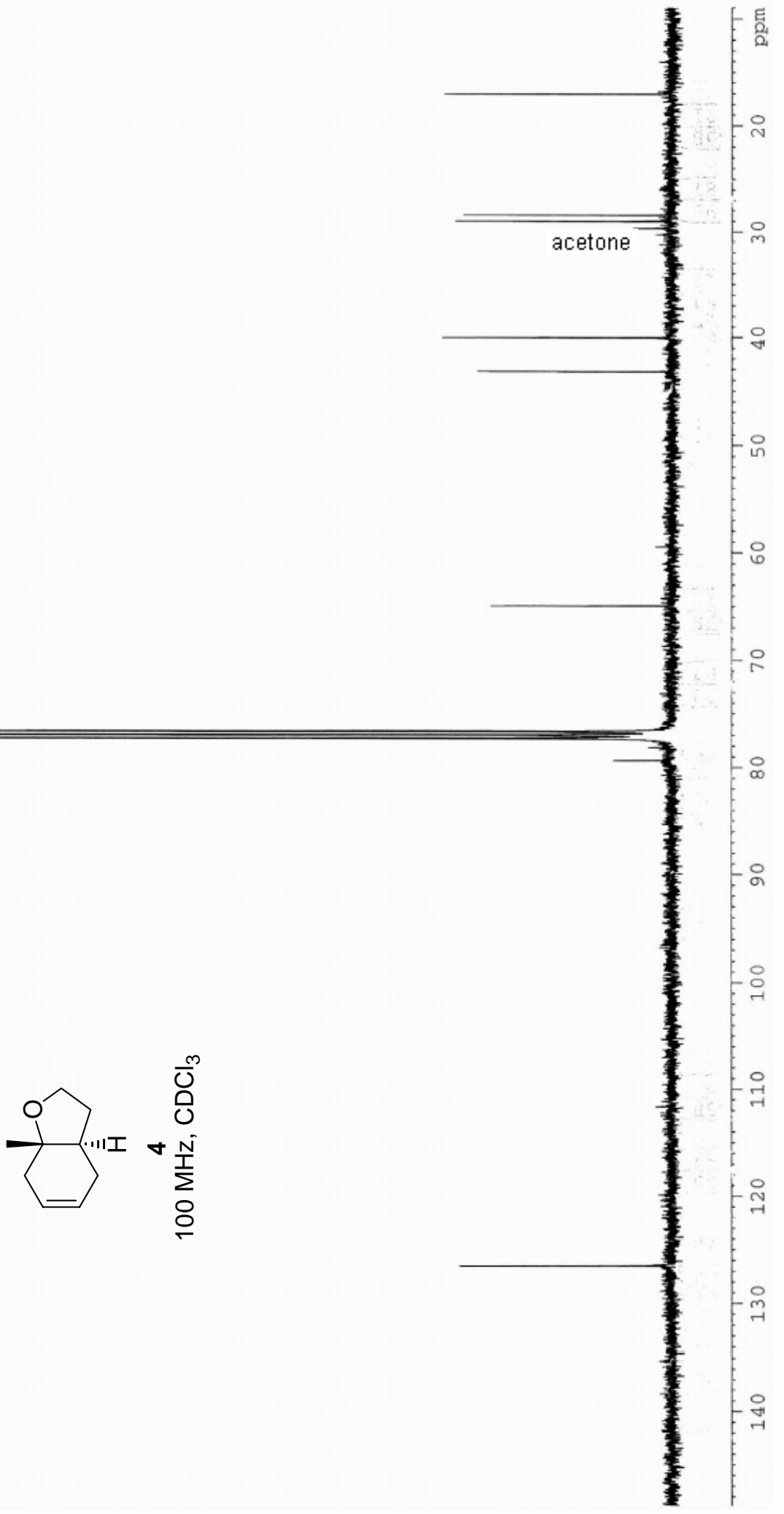


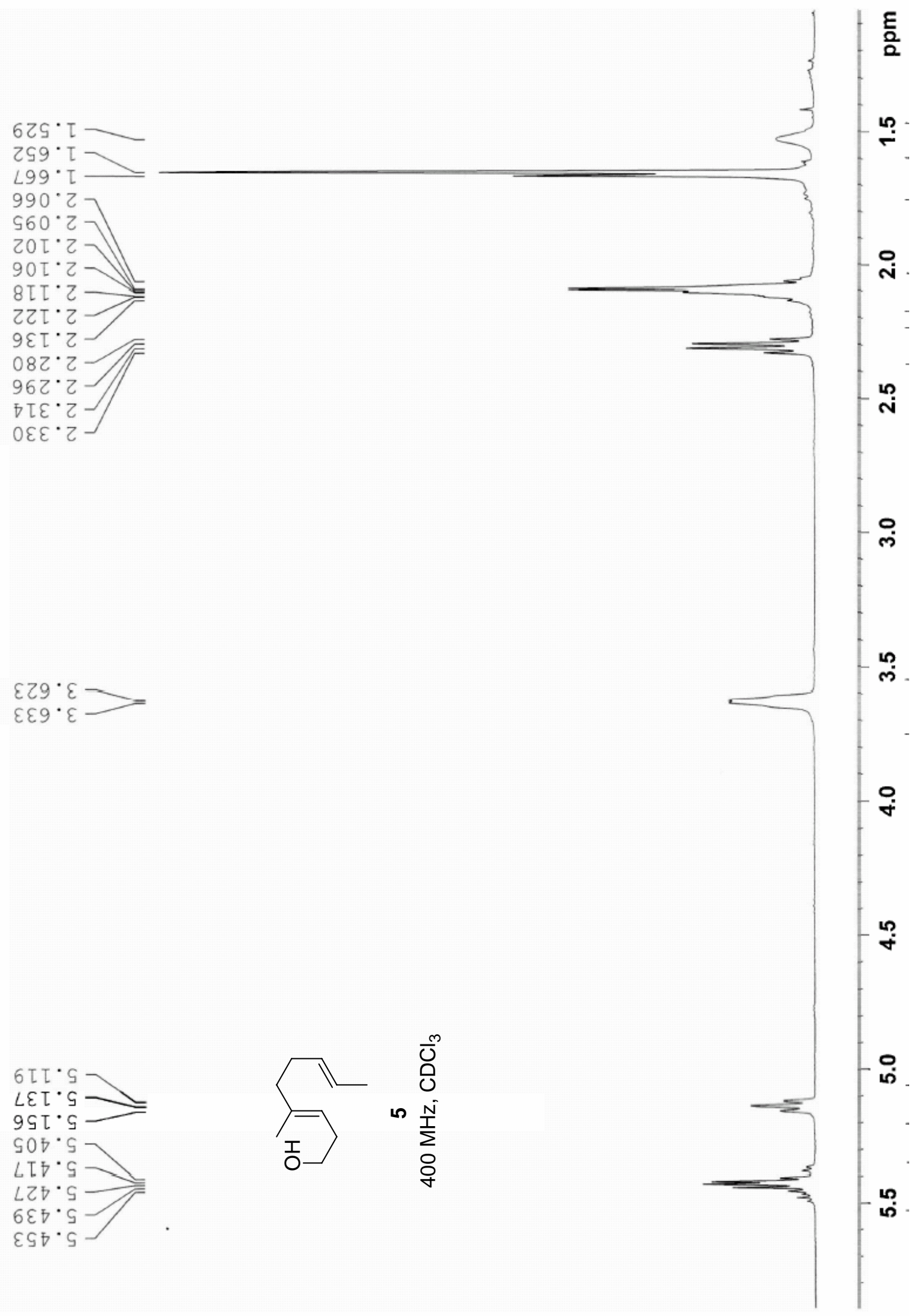




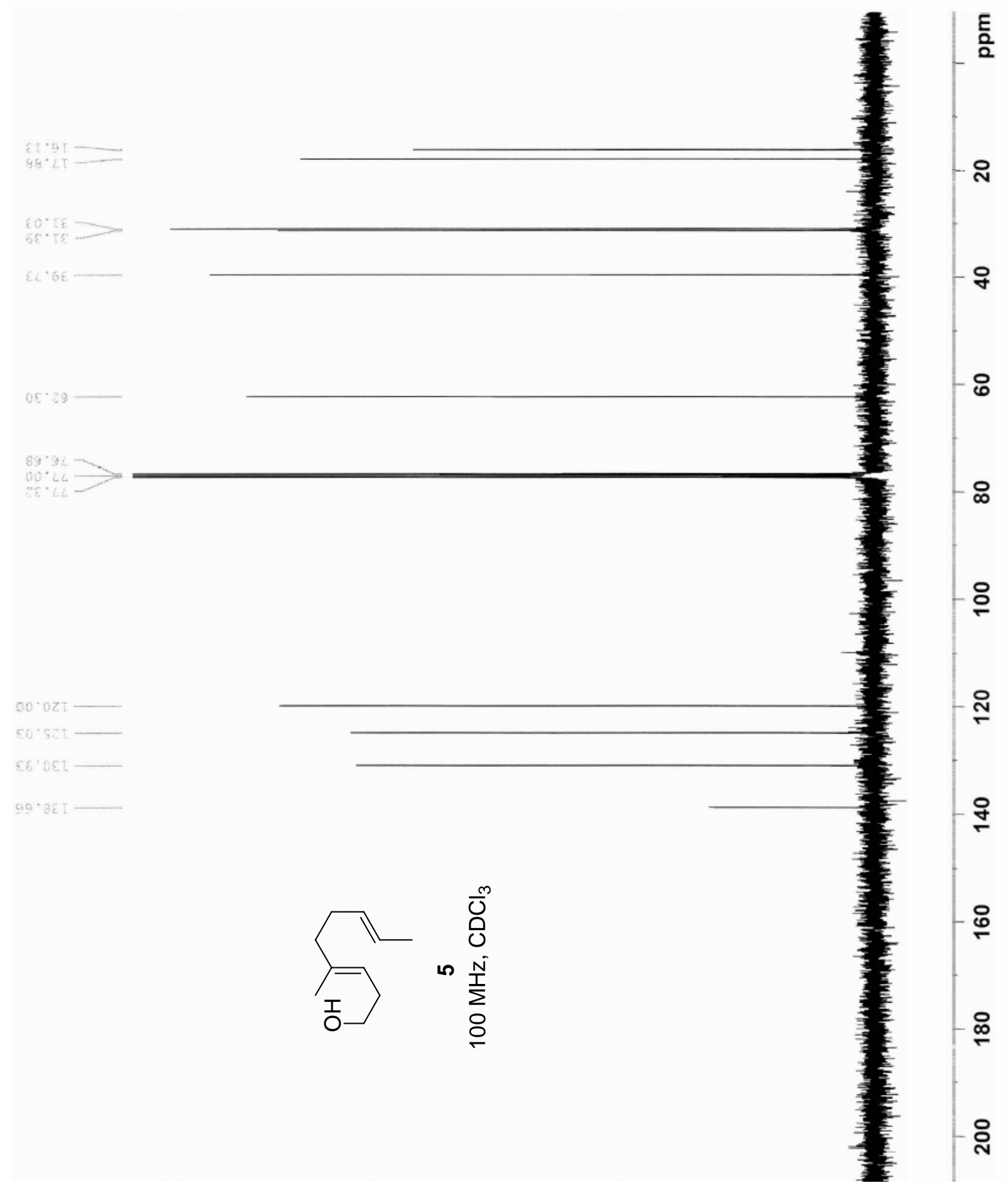



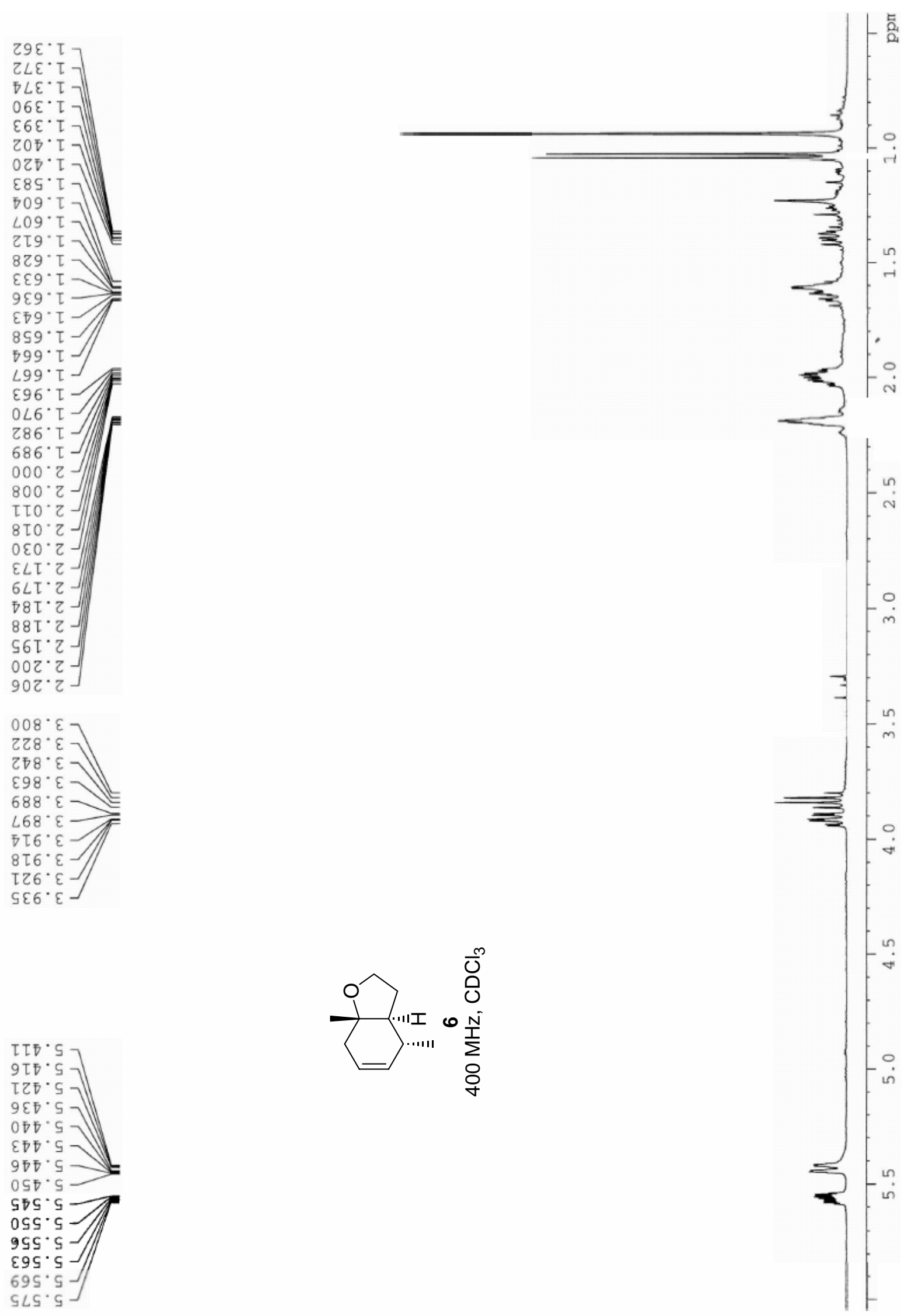


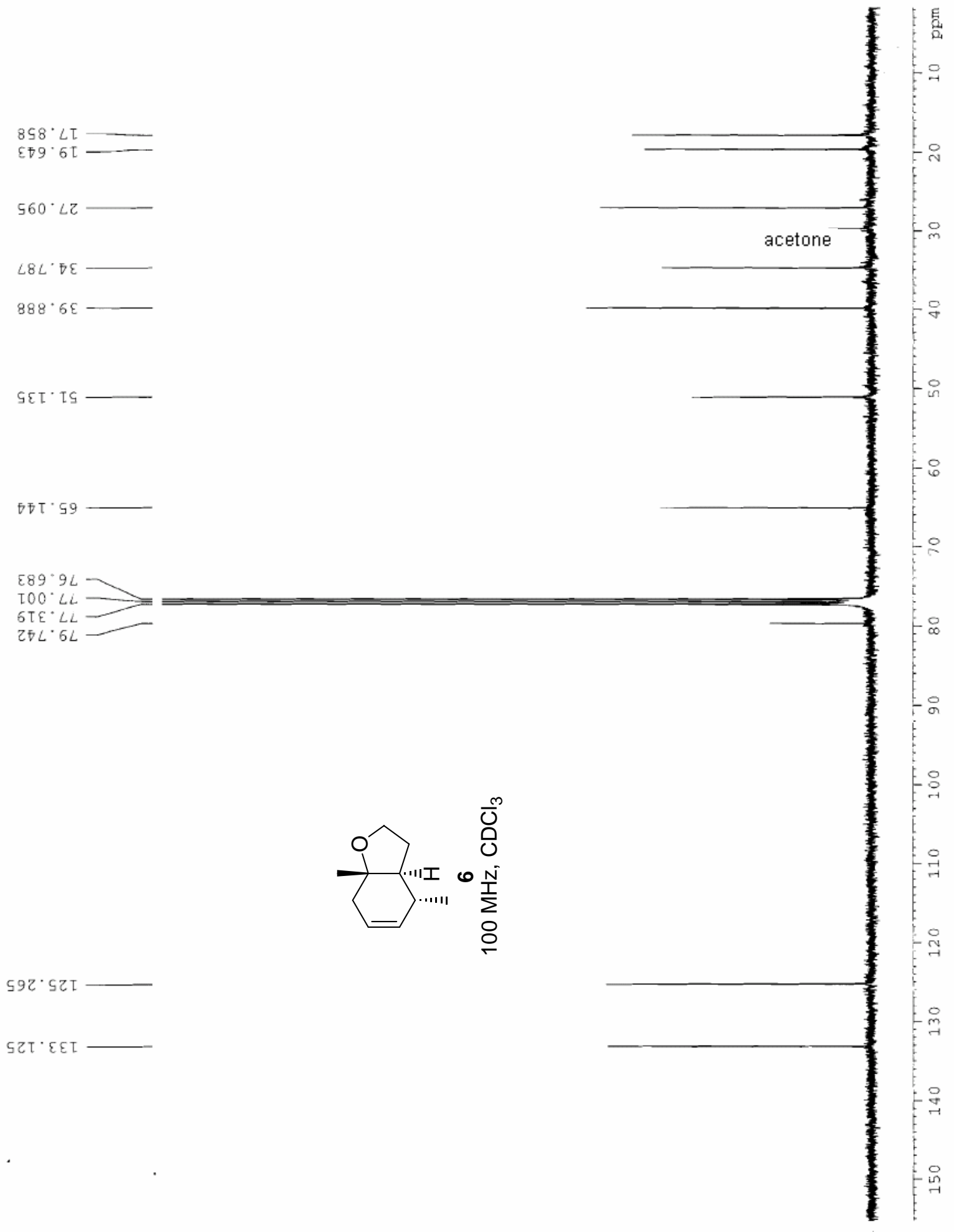


$2 \tau 6^{\circ} 0$

тย $6^{\circ}$

$606^{\circ} 0$

$89 \varepsilon^{\circ} \tau$

$\angle O D^{\circ}$

ZZ๐

$\angle E F^{\circ}$

$609^{\circ} \mathrm{T}$

วย9. $\tau$

$626^{\circ} \mathrm{T}$

$906 \cdot \tau]$

$876^{\circ} \mathrm{T}$

$796^{\circ} \mathrm{T}$

$\mathrm{Z86^{ \circ } \mathrm { T }}$

$000^{\circ} \mathrm{Z}$

与โ0 ${ }^{\circ}$

$\angle 20^{\circ} \mathrm{Z}$

$550^{\circ} \mathrm{Z}$

$890^{\circ} 2$

โ80.

$\varepsilon 80^{\circ}$

$\angle 60^{\circ}$

จะ乙 Z

โรZ 2

$89 \mathrm{Z}^{\circ} \mathrm{Z}$

$\mathrm{s} 8 \mathrm{Z} \cdot \mathrm{z}$
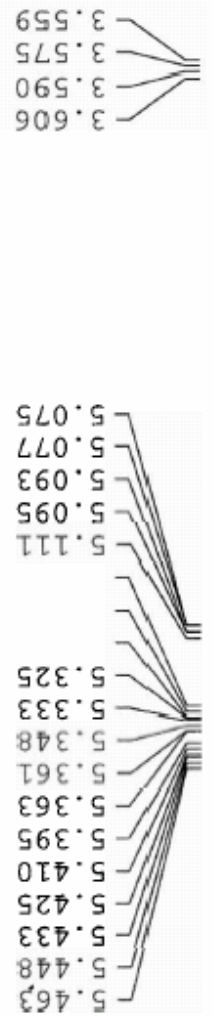

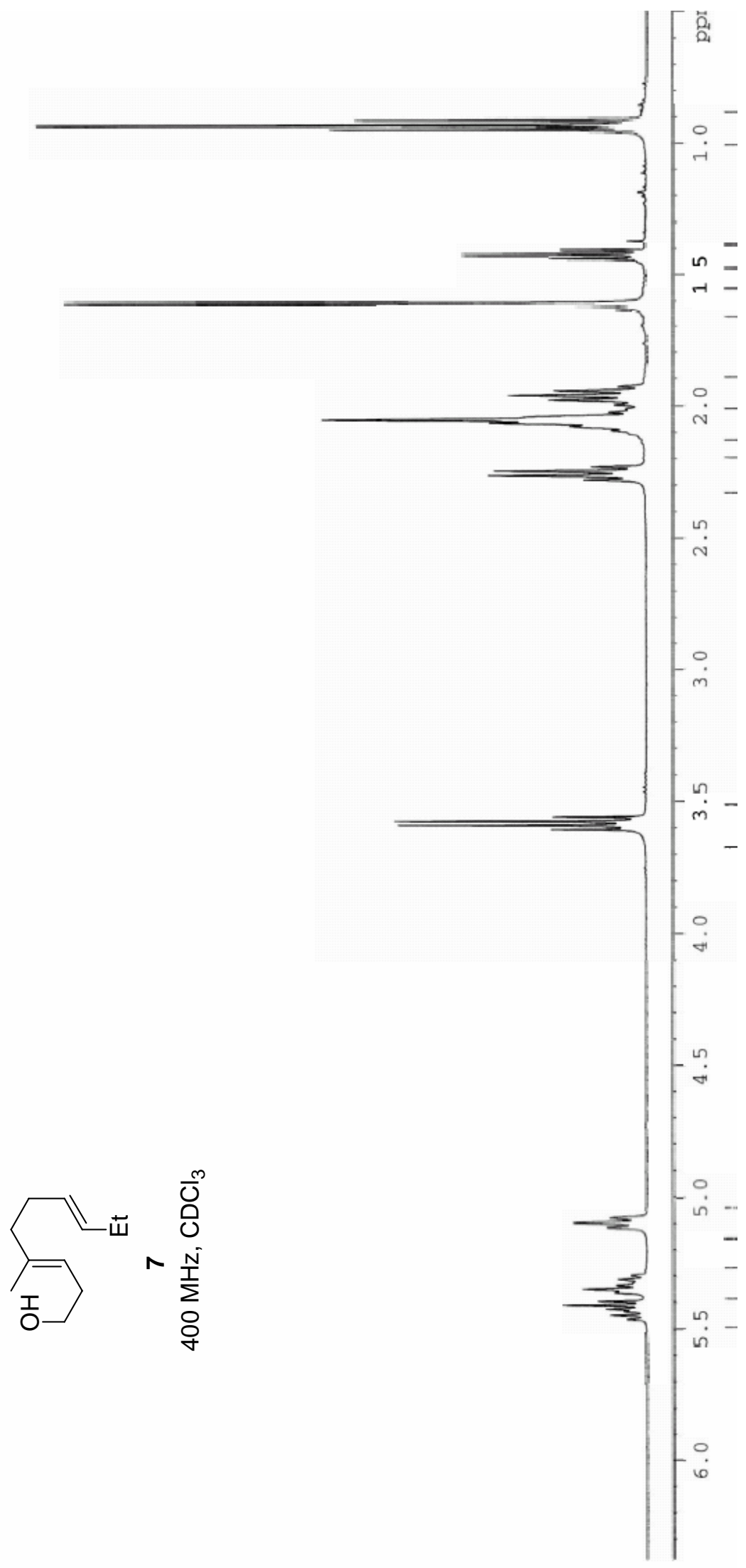

S-18 


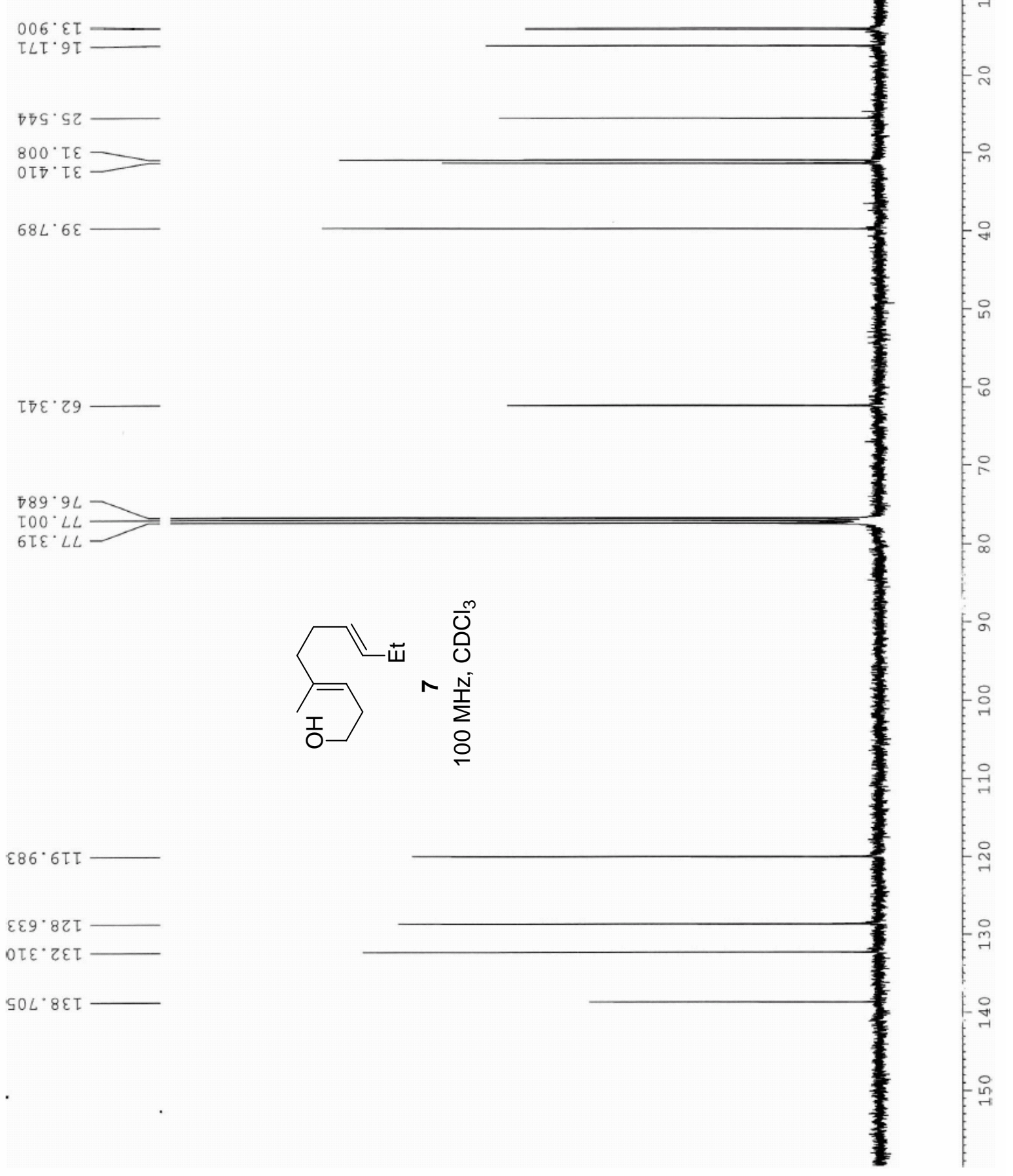



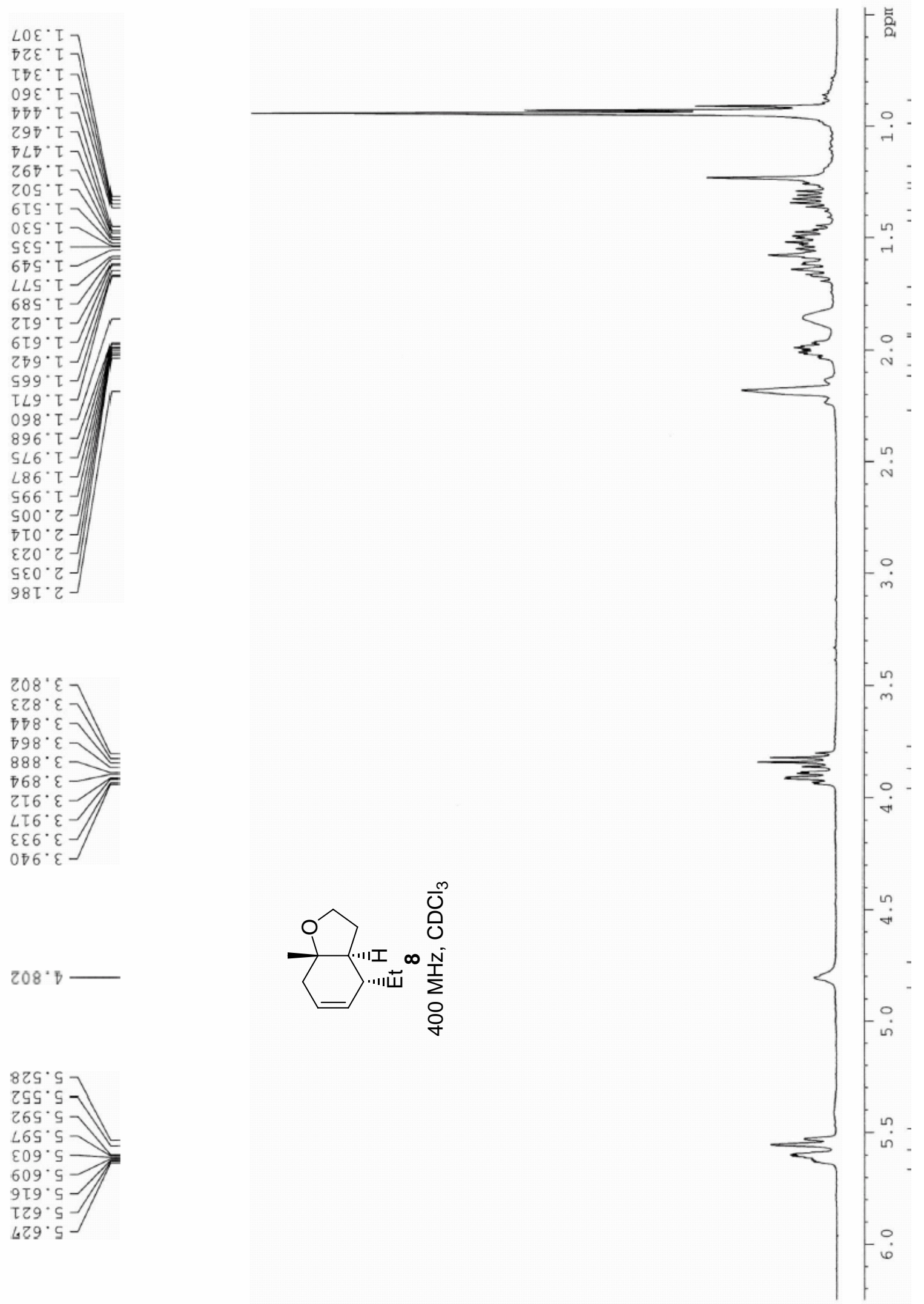

$208^{\circ} 7$

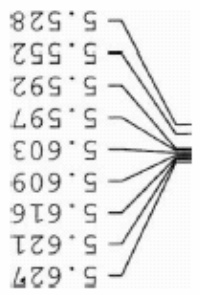


$928 \cdot L \tau$

$68 \mathrm{~s} \cdot 9 \mathrm{Z}$

$662^{\circ} \angle 2$

$\angle 89^{\circ} 62=$

SE6. $6 \varepsilon-$

จ० $\varepsilon^{\circ}$.

$909 \cdot 80$

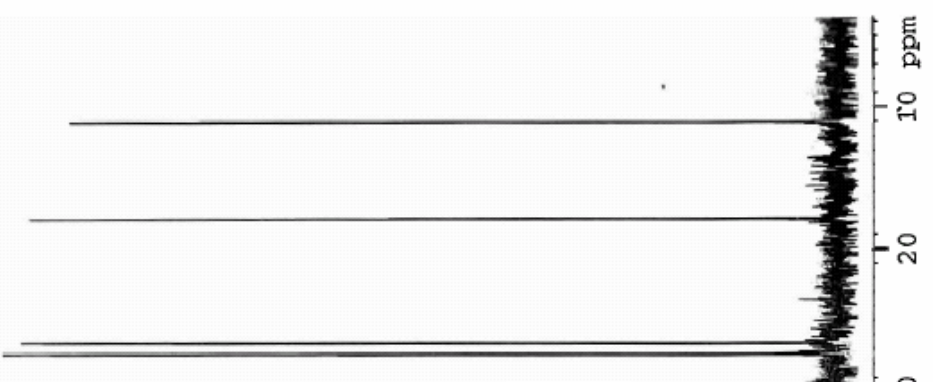

ธ२२·ร9

$589.9 L$

$200^{\circ} \mathrm{LL} \longrightarrow$

$S 0 Z^{\circ} \angle L$

$856 \cdot 6 L$

$856^{\circ} 6 L$

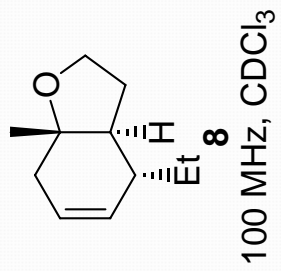

acetone
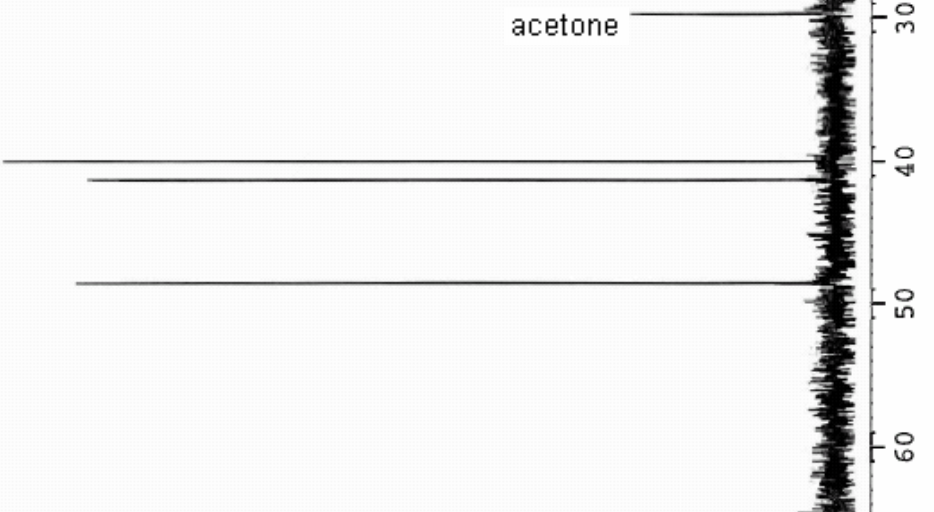


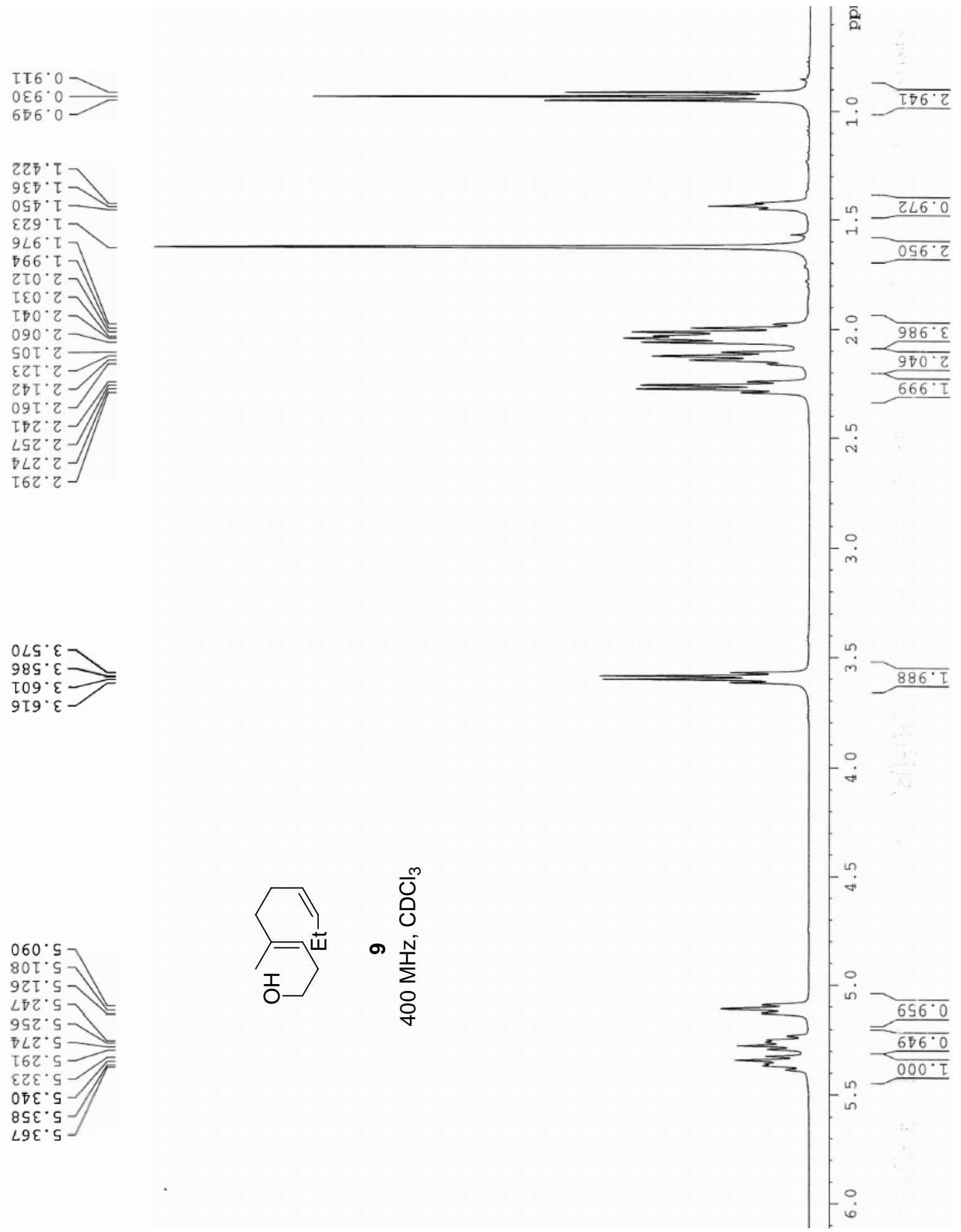



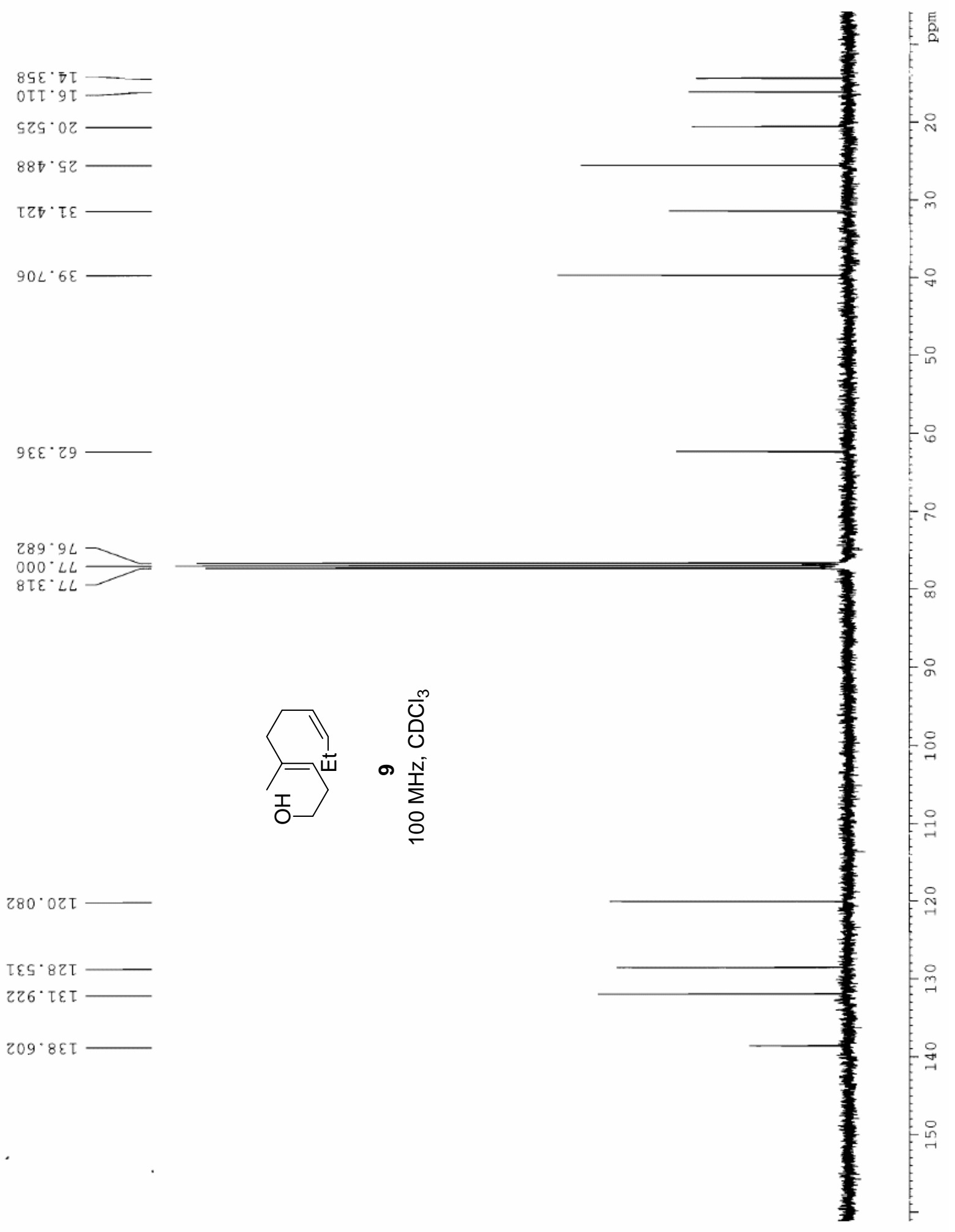

$280^{\circ} 0 Z \mathrm{~T}$

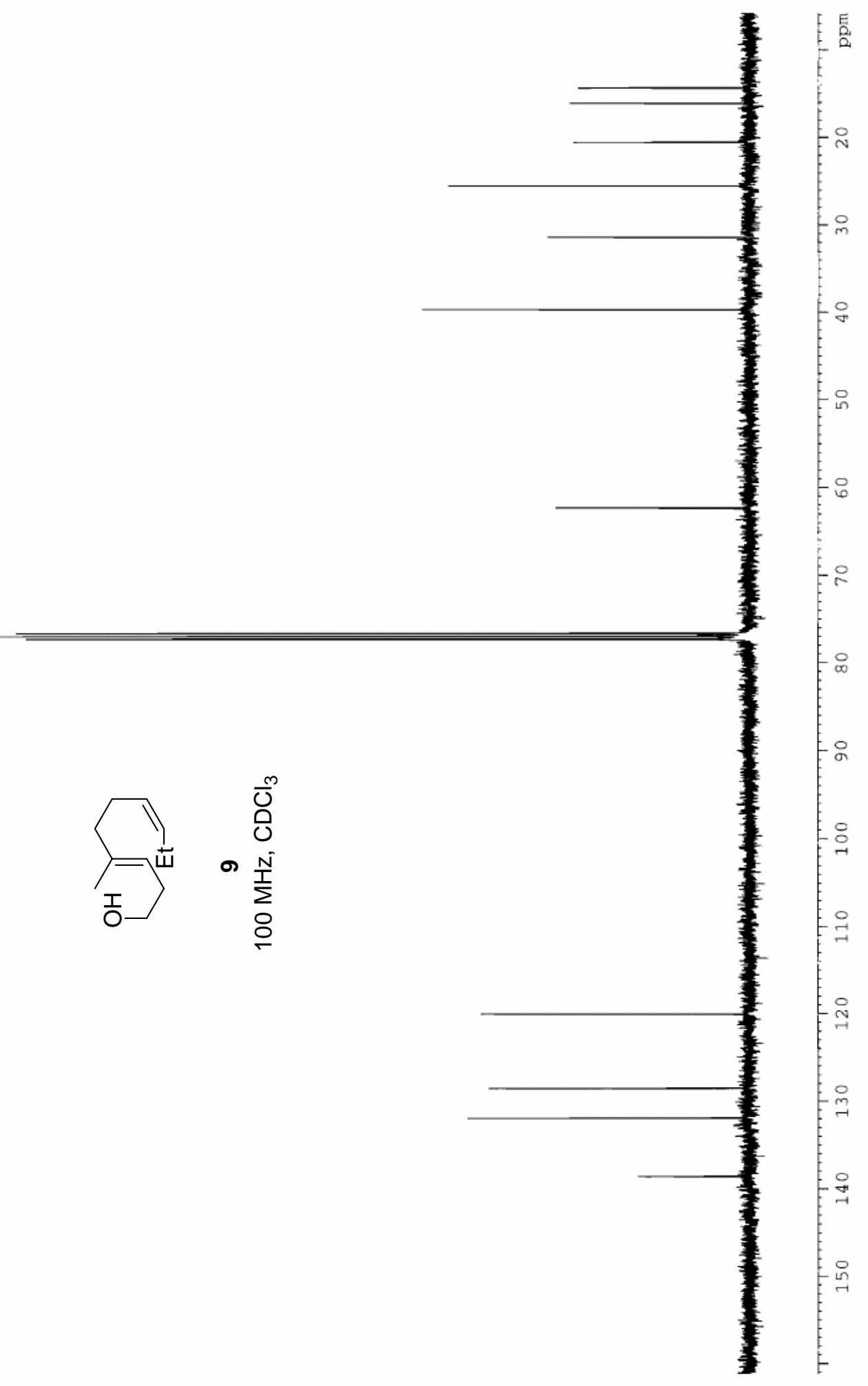

โ६૬.8ZT -

$226^{\circ} \tau \varepsilon \tau$

$209^{\circ} 8 \varepsilon \tau$ 

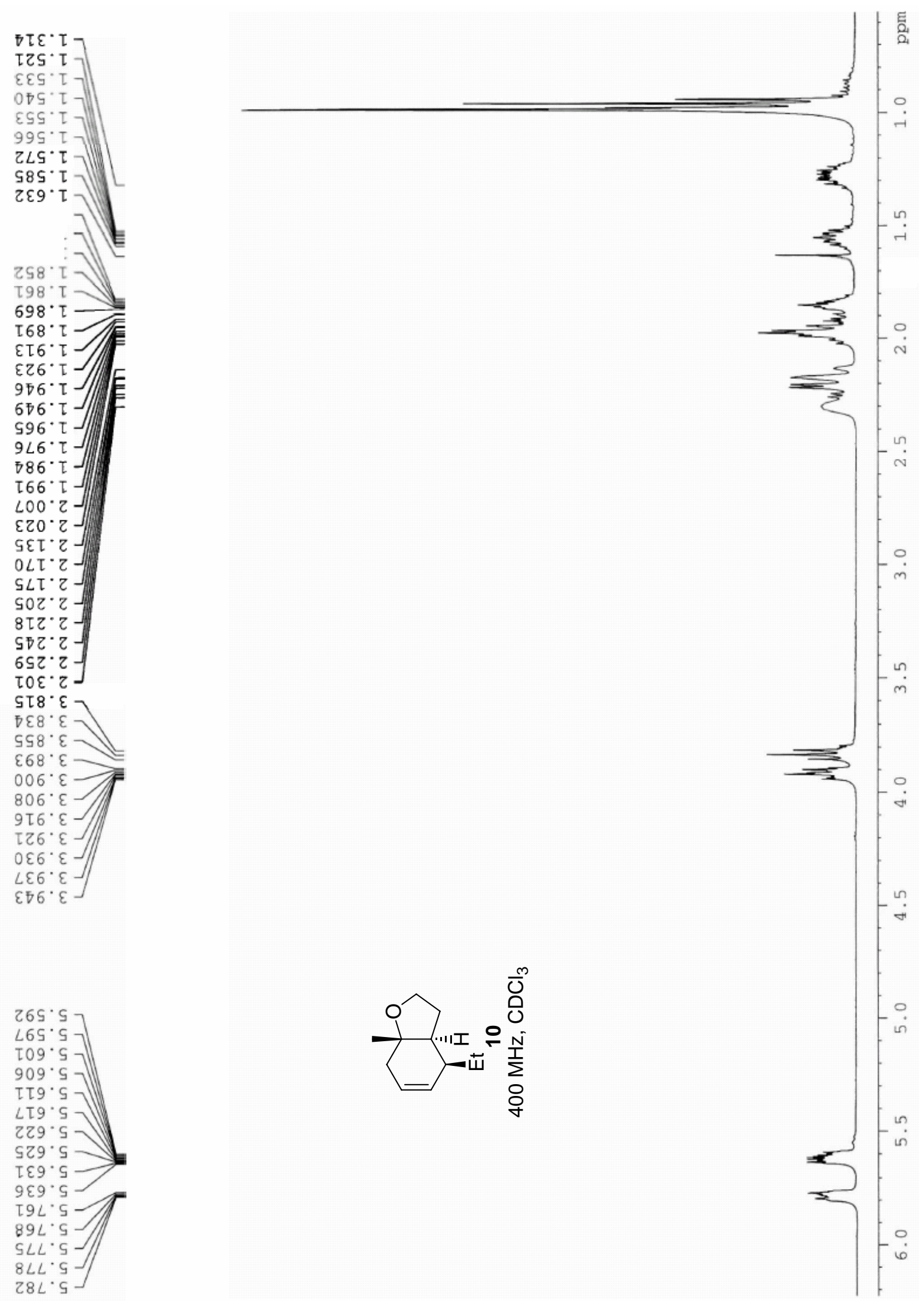


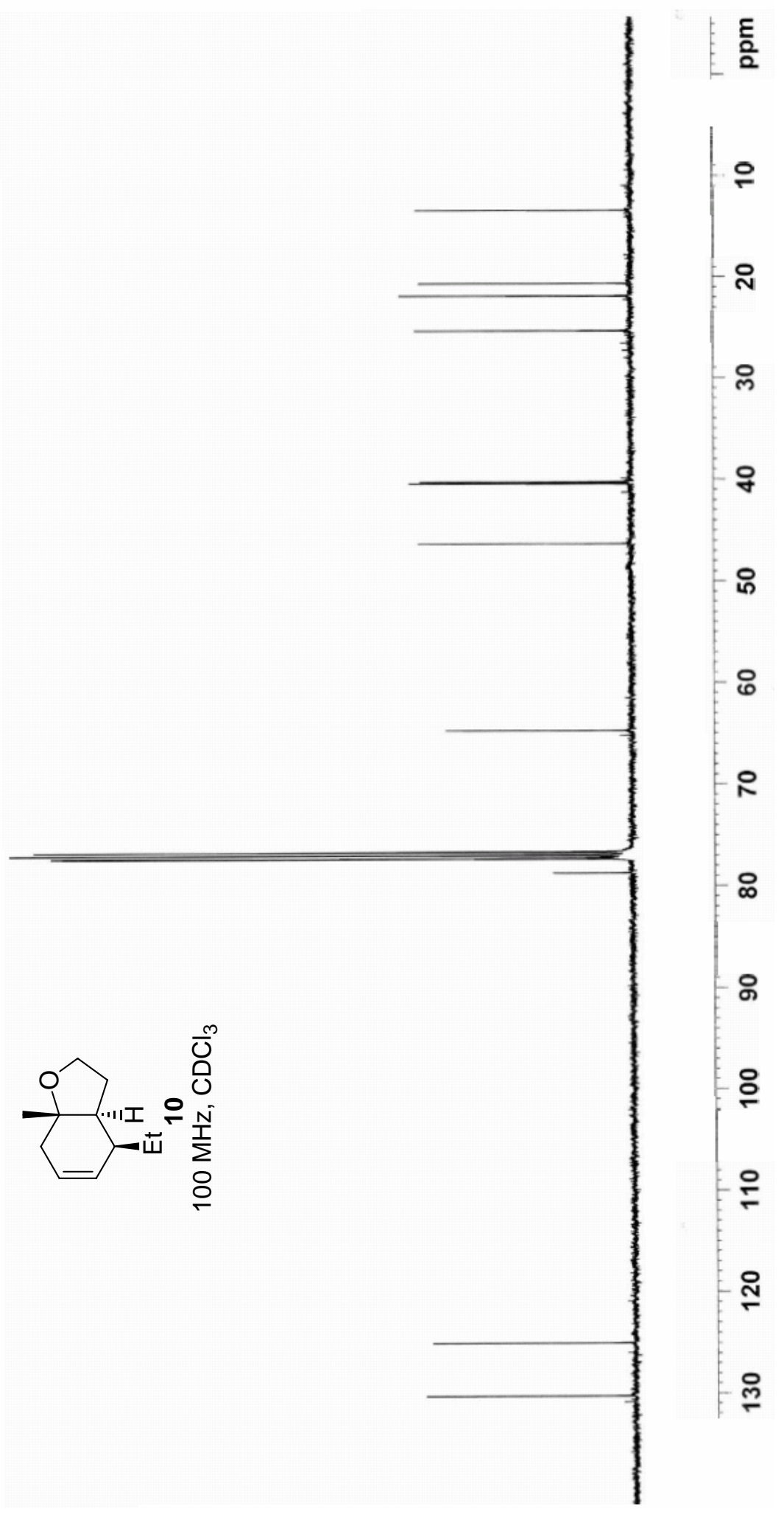



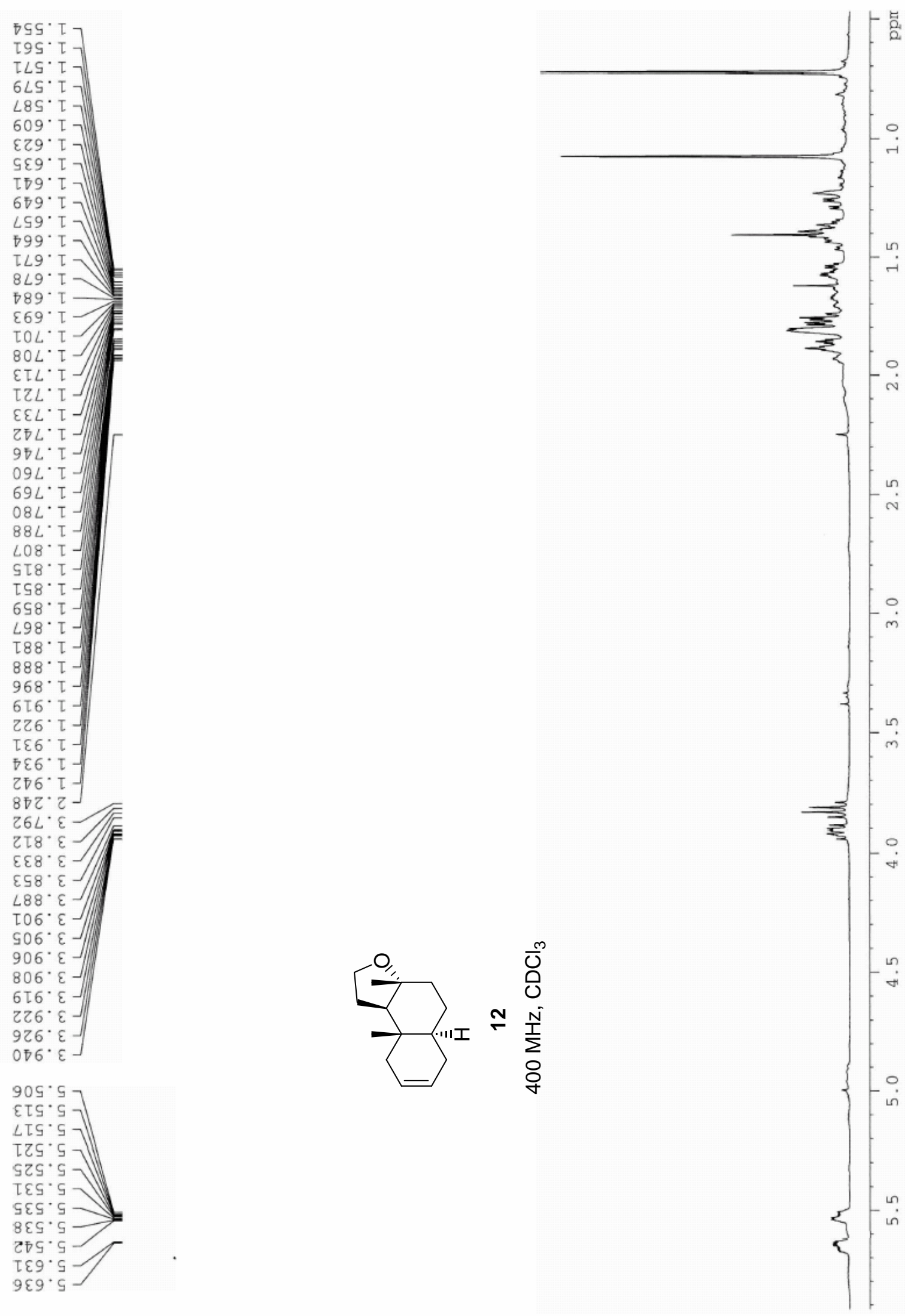


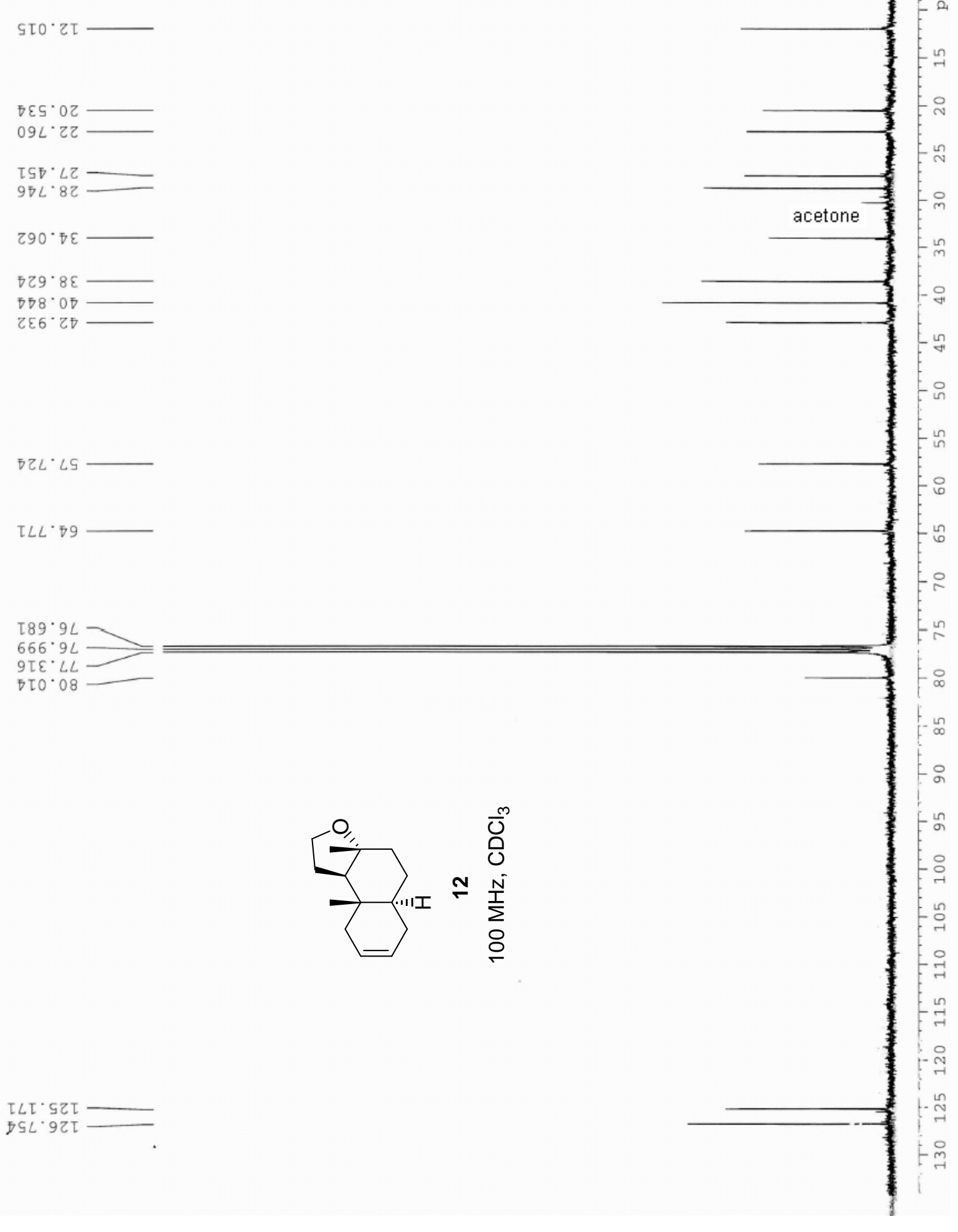



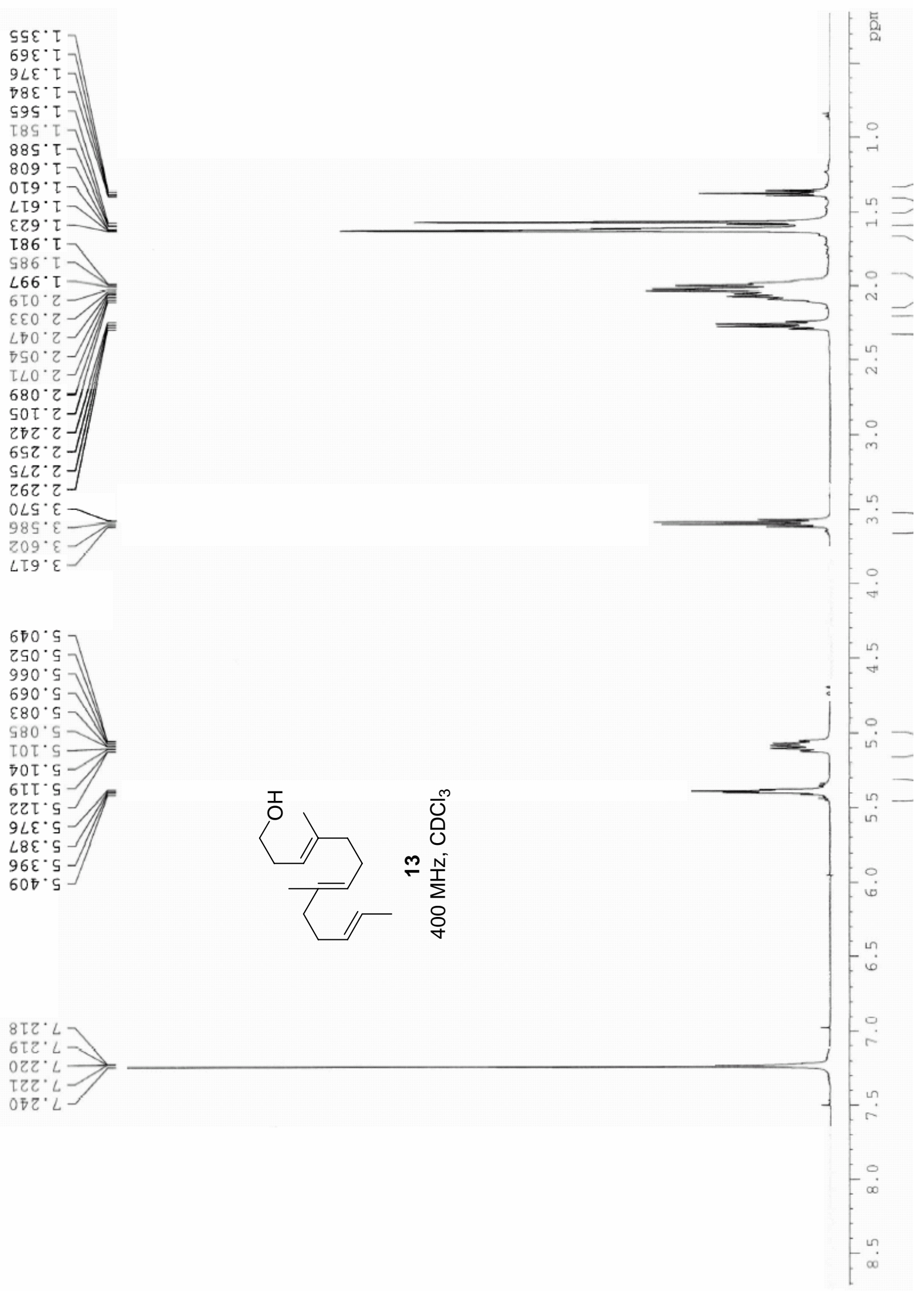
j)

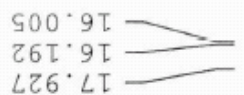

$\angle 26^{\circ} \mathrm{LI}$

万TF.9Z

$\nabla ट Z \cdot \tau \varepsilon$

$0 \angle D^{\circ} \tau \varepsilon \longrightarrow$

$6 L 9^{\circ} 6 \varepsilon \square$

$S L L \cdot 6 \varepsilon-$

$2 \tau \nabla \cdot 29$

$989^{\circ} 9 L$

$700^{\circ} \mathrm{LL}$

ZTZ' $L L$

Т乙E. $L L \longrightarrow$

$978^{\circ} 6 \tau \tau$

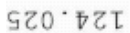

$989^{\circ}$ DZT

$\varpi \varepsilon \tau \cdot \tau \varepsilon \tau$

โLO ૬ع

$0 \tau 6 \cdot 8 \varepsilon \tau$

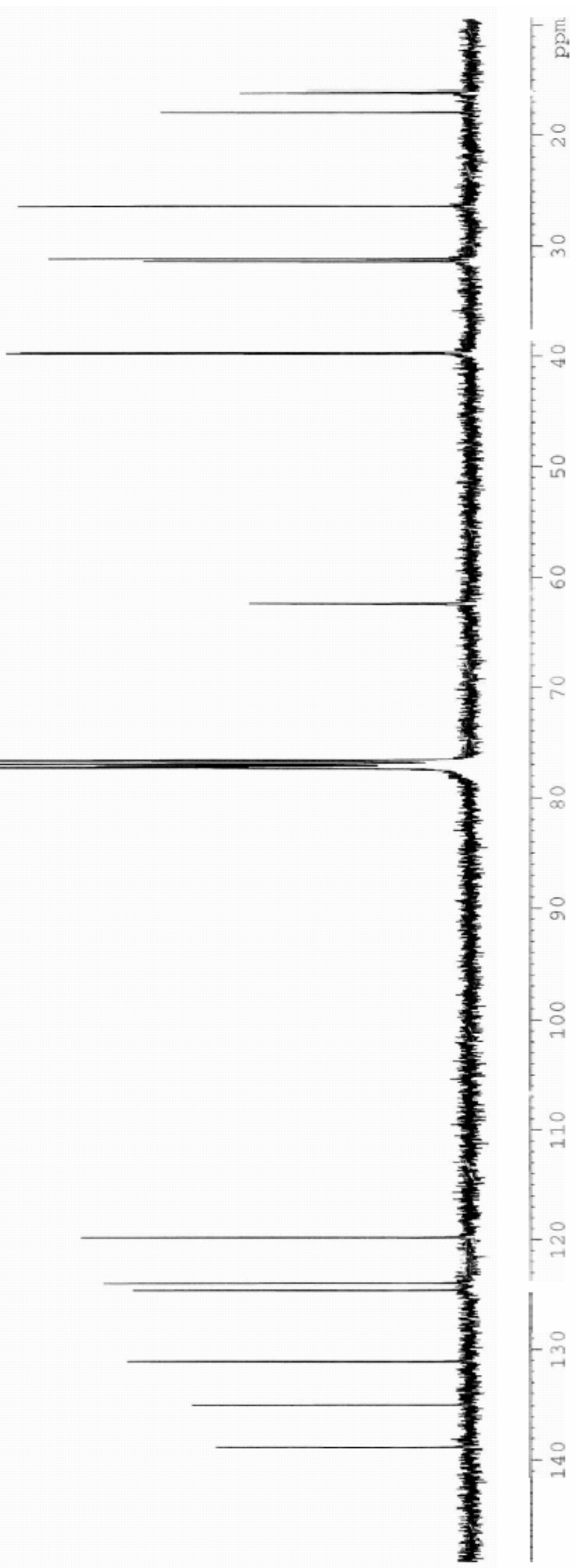



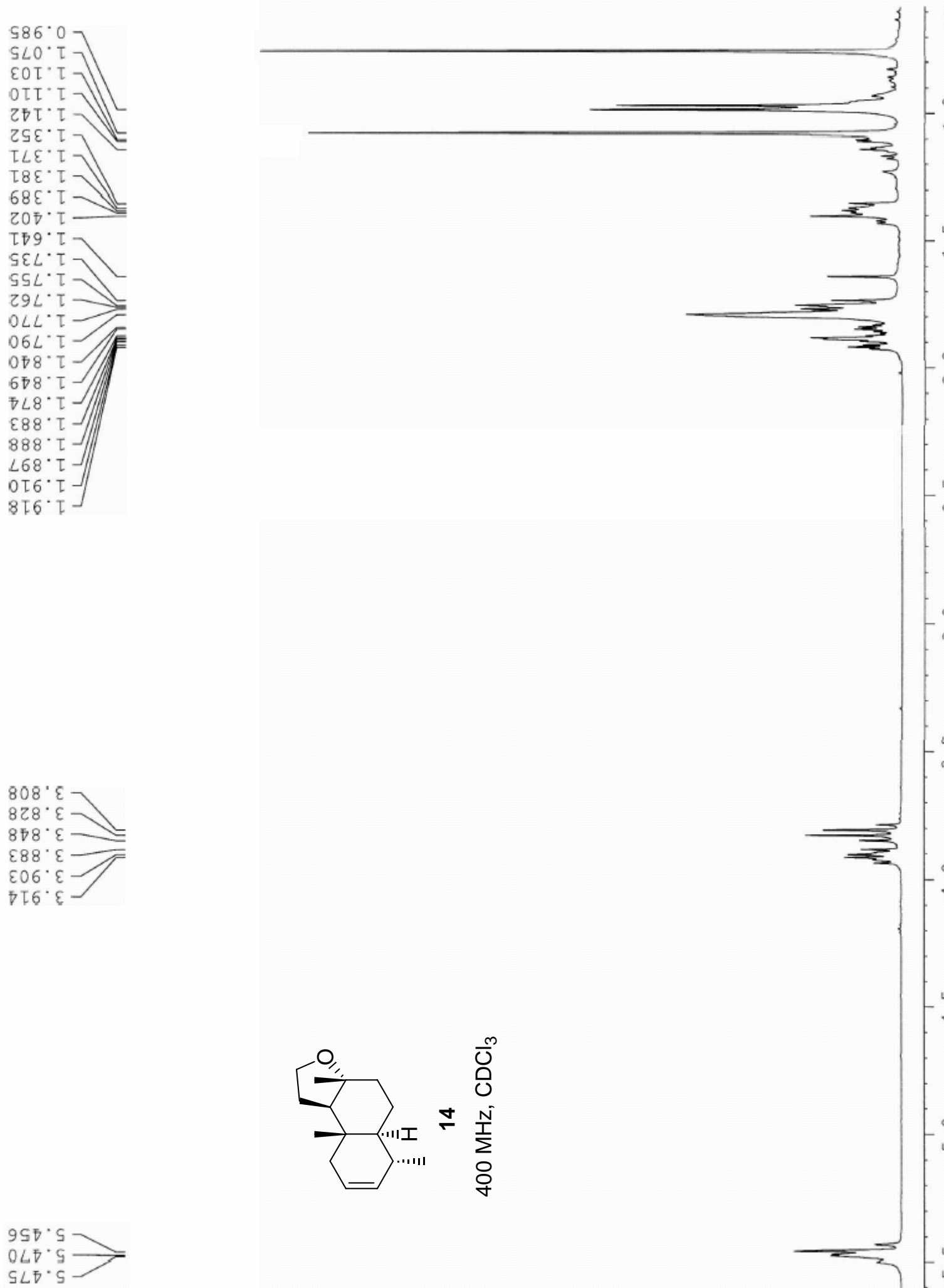

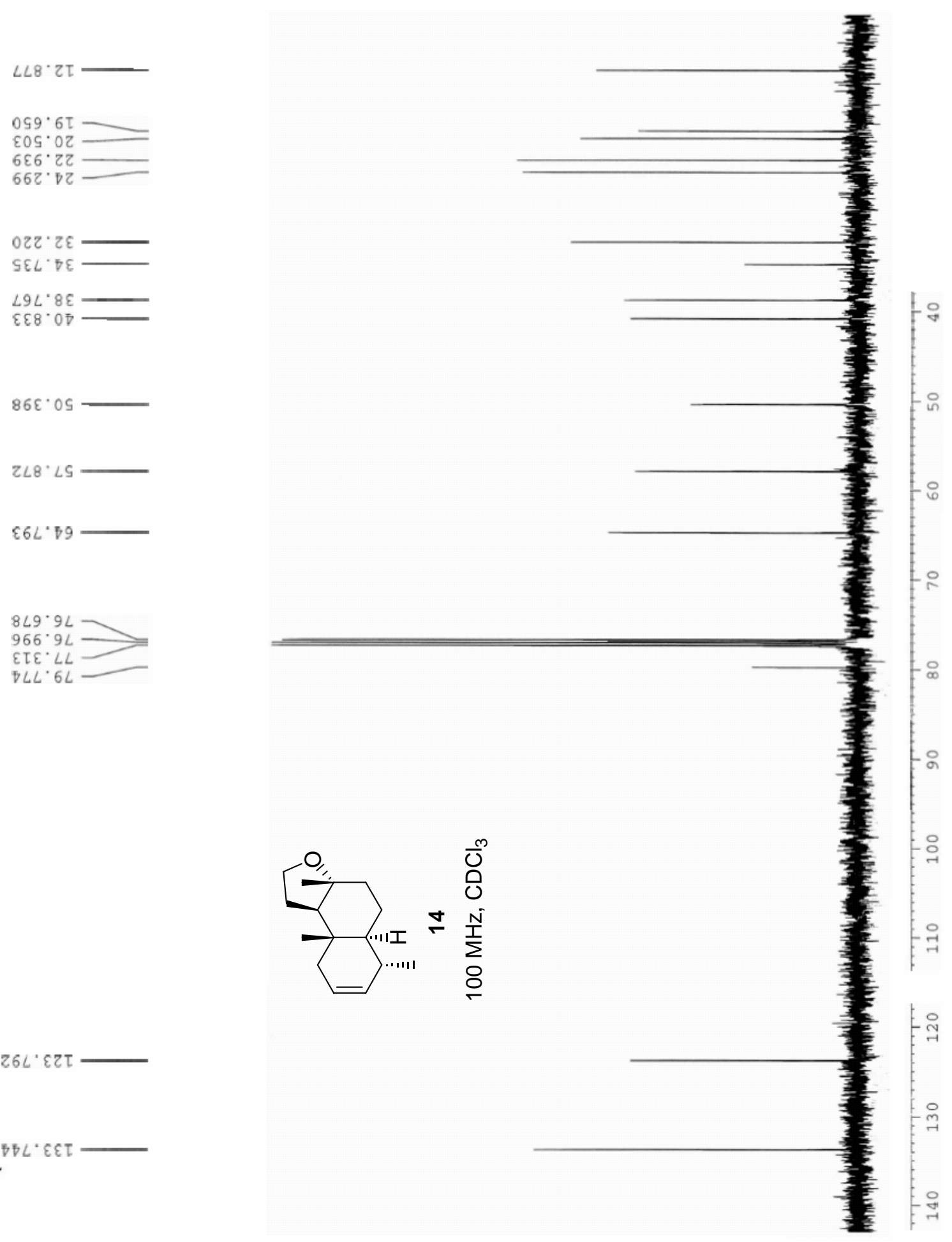

$26 L^{\prime} \varepsilon Z \tau-$

$\nabla \varpi L \cdot \varepsilon \varepsilon \tau-$ 

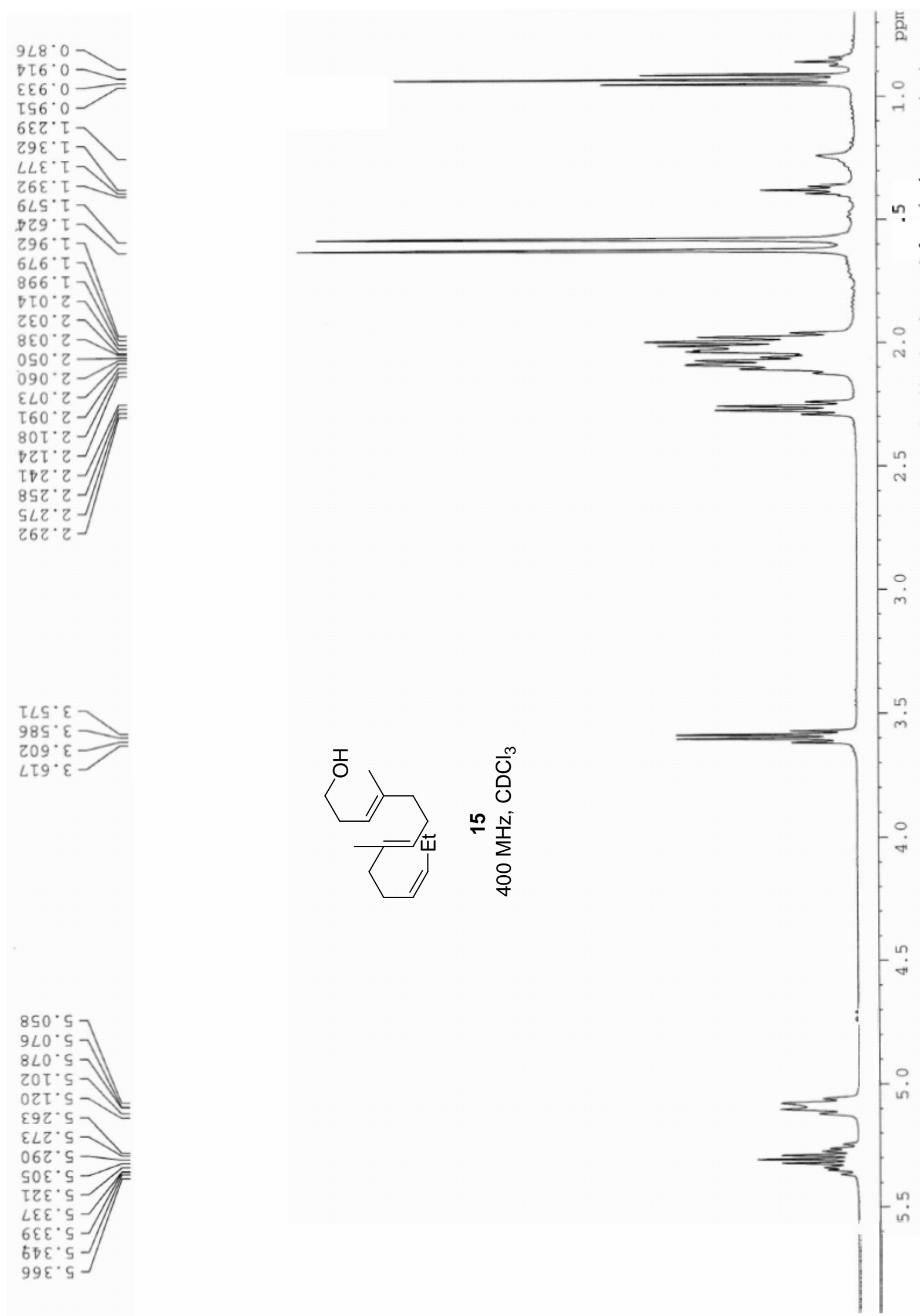

$\tau \angle S^{\circ} \varepsilon>$ $98 \mathrm{~S}^{\circ} \varepsilon$

$209^{\circ} \varepsilon$
$\angle \tau 9^{\circ} \varepsilon$

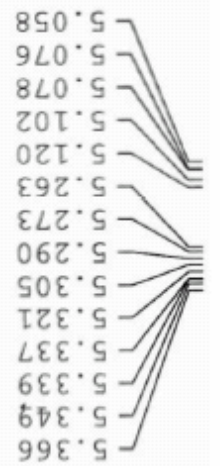




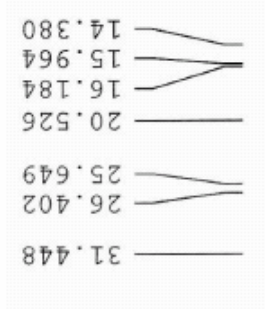

$709^{\circ} 6 \varepsilon \square$
$\varepsilon 9 L^{\circ} 6 \varepsilon$
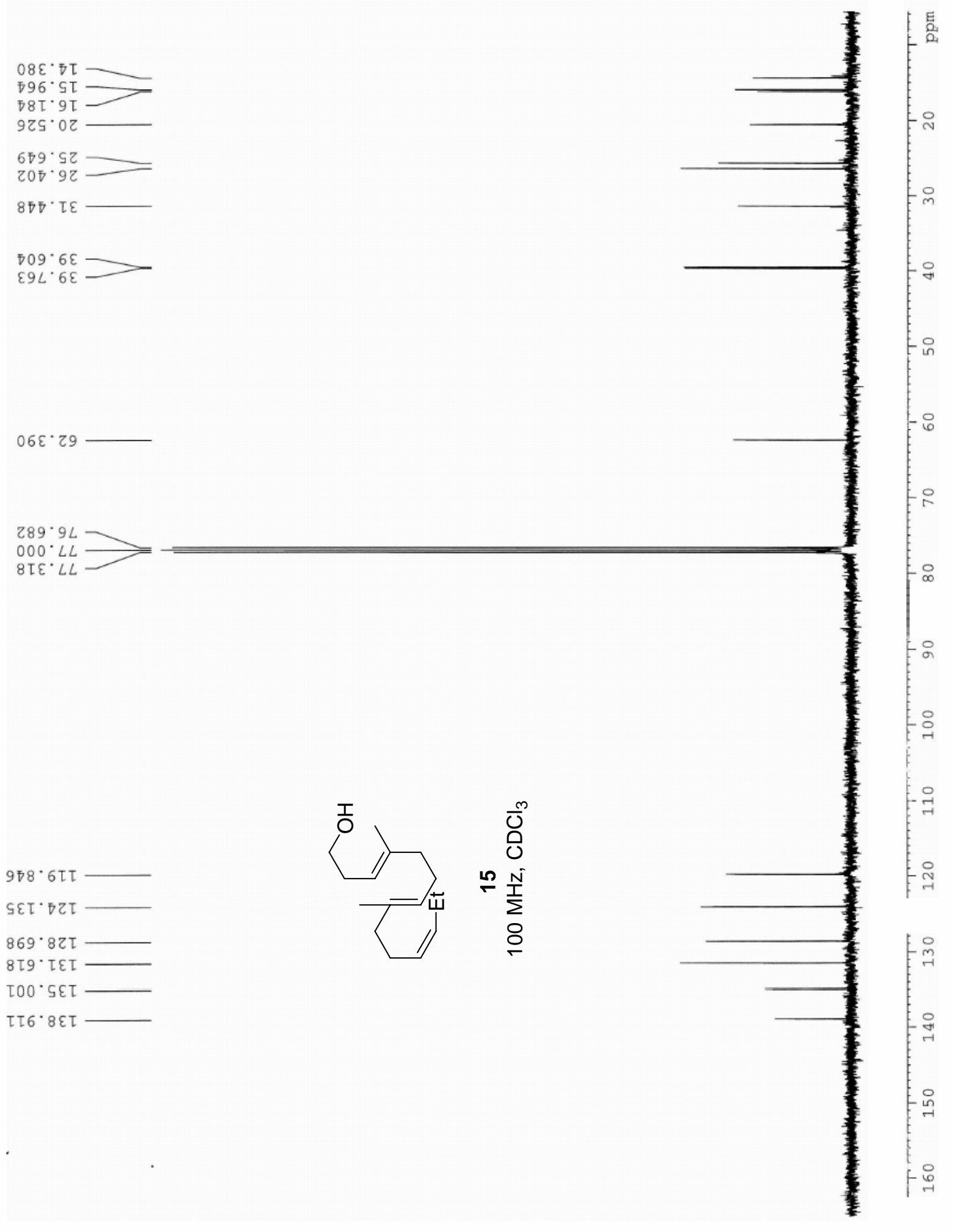

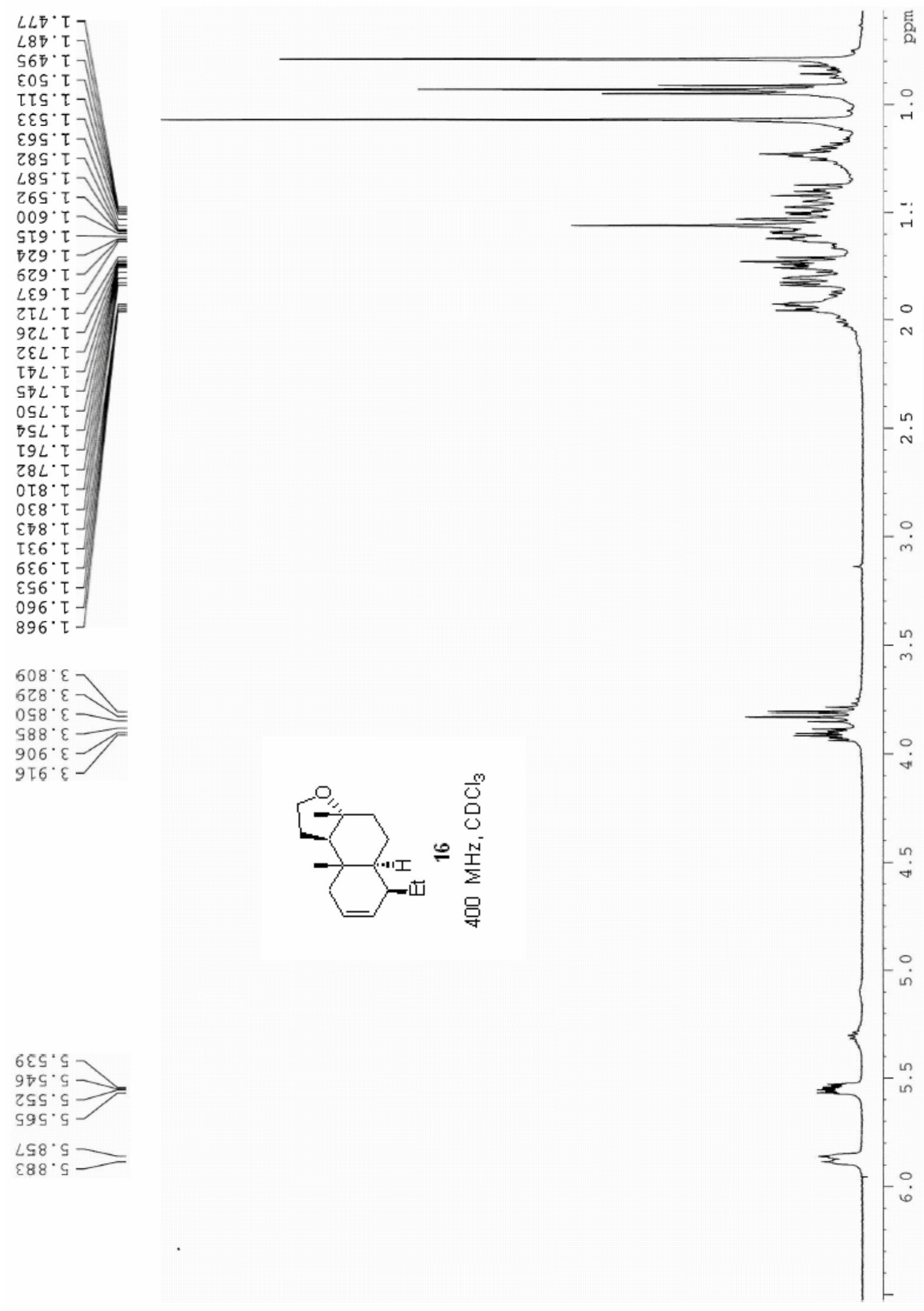

6ES'S

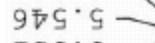

ZS. S

$\mathrm{S95}^{\circ} \mathrm{S}$

$\angle 8^{\circ} \mathrm{S}$

$\varepsilon 88^{\circ} \mathrm{s} \longrightarrow$ 


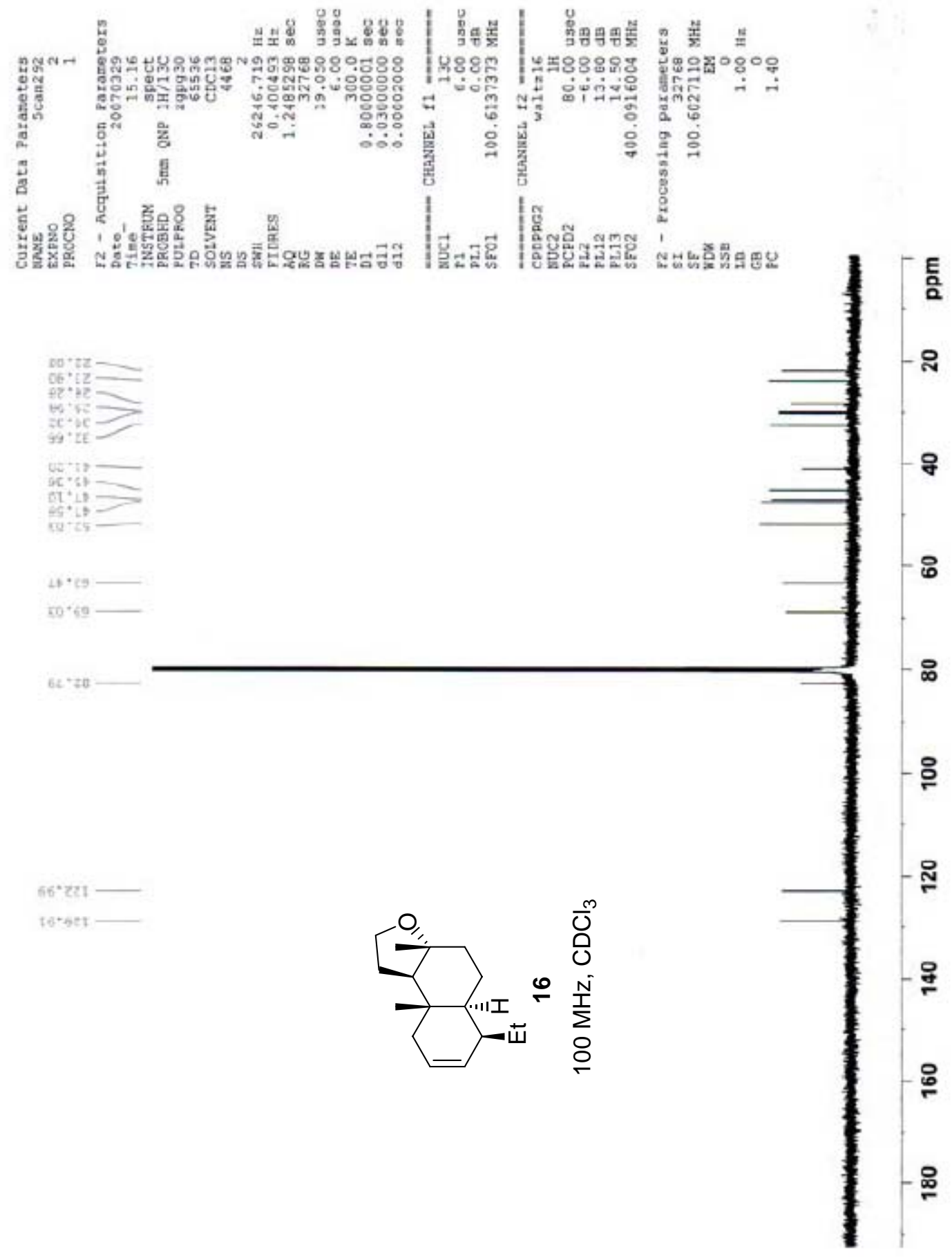

